\title{
Experimental analysis of process parameters in drilling nimonic C263 alloy under nano fluid mixed MQL environment
}

\author{
Chakaravarthy Ezilarasan ${ }^{1}$, Meenaskshi Sundaram Nagaraj ${ }^{2,}{ }^{*}$, A. John Presin Kumar ${ }^{3}$, \\ A. Velayudham ${ }^{4}$, and Rishab Betala ${ }^{5}$ \\ ${ }^{1}$ Department of Mechatronics Engineering, Chennai Institute of Technology, Chennai 600069, India \\ 2 Department of Mechanical Engineering, MNM Jain Engineering College, Chennai600097, India \\ 3 Department of Mechanical Engineering, Hindustan Institute of Technology and Science, Padur, Chennai 603103, India \\ ${ }^{4}$ Former Scientist F, CVRDE and Visiting Professor, Department of Manufacturing Engineering, Anna university, Chennai. \\ ${ }^{5}$ ARE PEE Polymer, Gummidipoondi, Tiruvallur 601201, India
}

Received: 3 October 2020 / Accepted: 19 December 2020

\begin{abstract}
Nimonic C263 is a super alloy and it is difficult to cut. As this alloy possess high proportion of chromium, cobalt, and molybdenum, which fortify the material by solution hardening, which inhibits the dislocation movement, resulting in higher plastic deformation. In this research, an attempt has been made to model, analysis and investigate the machining characteristics such as thrust force, temperature at drill cutting edge, flank wear and surface finish during drilling of this alloy using silver nano fluid mixed Minimum Quantity Lubrication (MQL) environment. Residual stress at various combinations of process parameters was also observed and discussed. RSM based empirical models of the process parameters and optimization of multi response was developed. Thrust force, Temperature at drill cutting edge, surface roughness and tool wear affected by feed rate (percentage of contribution-60\%), spindle speed (percentage of contribution-88.63\%), spindle speed (percentage of contribution-71.42\%) and feed rate (percentage of contribution-67.76\%) respectively followed by other parameters.
\end{abstract}

Keywords: Nimonic C263 / thrust force / temperature at drill cutting edge / surface roughness / flank wear / Nano fluid / MQL

\section{Introduction}

Nimonic C-263 alloy finds wide applications in aero engines, heat exchangers due to its special properties such as low thermal conductivity, high creep, high work hardening rate, good thermal fatigue, oxidation, and corrosion resistance. Nimonic C263 alloy is solution treated and precipitation hardened. Hence, it is tough to cut and need to find out suitable machining condition to produce quality surface and other manufacturing attributes. It has Gama precipitates and metallic carbides, and its cobalt content strengthens during solidification $[1,2]$. As Nimonic C263 is used in the aircraft engines which are continuously subjected to high temperature, its integrity has to be maintained and utmost care is to be taken during machining. As this alloy is expensive and also arduous to machine, these components have to be made with care to maintain the required quality and also need to resist the

\footnotetext{
* e-mail: nagaraj_magic@yahoo.co.in
}

fracture and fatigue during its usage, this alloy's integrity also should be maintained at high rate during machining. The presence of various metals in the Nimonic C263 alloy and their corresponding metallurgical characteristics pose a challenge when drilling. These properties impact the surface and the integrity, result in metallurgical changes, inaccuracy and reduce the service life of the machined parts. Nimonic C263 causes accelerated tool wear due to its work-hardening and high strength. Hood et al. [3] carried out a detailed investigation on surface integrity and drill wear when drilling the $\mathrm{Ni}$ based super alloy Haynes 282 using coated carbide drill under high pressure cutting fluid. They have suggested that, the coolant in high pressure applied in drilling produces better outputs. Erween et al. [4] analyzed the surface integrity in drilling Inconel 718 alloy under the minimum quantity of lubricant (MQL) condition and they used Palm oil and synthetic ester as the lubricant for the process. It was reported that the MQL provides the substantial benefits by providing Cause ive lubrication in the machining process. Lawal et al. [5] conducted an experiment considering the factors such as work piece 
material, cutting tool material in the machining process. The experiments were conducted under MQL environment by varying the factors level to analyse the machining performances. They used vegetable oil as the lubricant. Using this technique they have found the development in the overall performance of the machining characteristics.

Nazmul Ahasm et al. [6] analysed the performance machining characteristics, while machining under dry and minimum quantity of lubricant (MQL) environment. The responses such as dimensional deviation, surface roughness, temperature generation and drill wear were considered as output and it was reported that, under MQL condition were good than the responses observed by dry condition. Shyha et al. [7] have examined the cause of cutting fluids dependent on vegetable oil, cutting tool materials and working conditions in turning Ti-6Al-4V. The set of experimental plans was designed to assess performance characteristics such as roughness of the surface and wear of the tool flank. Kuzu et al. [8] conducted deep hole drilling study with MQL set-up on Graphite Iron and validated the experimental values of thrust force and drilling temperature through finite element model. Swain et al. [9] performed micro-drilling experiment on Nimonic $80 \mathrm{~A}$ to investigate drill wear, surface roughness and hole diameter using uncoated and coated TiAlN drills. The spindle speed, feed rate, and dill diameter were considered as input parameters. The results showed that the uncoated TiAlN drill was easily worn out and also affected the quality of the dilled holes when the spindle speed and feed rate increased. Bose et al. [10] used nano fluid in the machining of Nicrofer C263 alloy under nano fuel mixed MQL condition. Aluminium oxide was considered as nano fluid. The results showed that, the use of nano fluid mixed MQL condition gives the better surface finish and good temperature dissipation in the cutting zone compared to other lubricant condition. Revuru et al. [11] has discussed the temperature parameters with different cutting fluids. In any metal cutting operation, a lot of heat is generated due to plastic deformation of work material, friction at the tool-chip and tool work piece. Liberation of heat when machining in dry condition will cause unforeseen quality issues. Thus, fluids aiding the cuts now seem uncontributing to adress all the intended issue.

Oluwole et al. [12] have conducted drilling experiments on Rene 65 super alloys. The machining characteristics such as surface finish, thrust forces and chip formations were investigated at different cutting conditions. The experiments were also carried out to evaluate the effects of different hardness of Rene 65 alloys on the machining characteristics. They have observed that, hardness ranging $41 \mathrm{HRC}$ to $52 \mathrm{HRC}$ and spindle speed did not influence much on the thrust force. Feed rate is influenced much on thrust force and chip formation. Darshan et al. [13] have conducted turning experiments on Inconel 718 and they have reported that, the machining characteristics such as temperature at the cutting zone, surface finish and tool wear reduced in turning this alloy under $\mathrm{MoS}_{2}$ nano fluid MQL environment as this fluid has high thermal conductivity. From the literature, it was found that, there was no adequate study on the evaluation of the causes of drilling variables on the machining characteristics in
Table 1. Chemical composition of Nimonic C263 alloy.

\begin{tabular}{llc}
\hline S. no & Compositions & Wt in \% \\
\hline 1 & Nickel & 52.49 \\
2 & Silicon & 0.19 \\
3 & Manganese & 0.46 \\
4 & Chromium & 20.0 \\
5 & Molybdenum & 6.29 \\
6 & Copper & 0.07 \\
7 & Iron & 1.0 \\
8 & Cobalt & 16.7 \\
9 & Titanium & 1.94 \\
10 & Tungsten & 0.15 \\
11 & Aluminum & 0.48 \\
12 & Niobium & 0.04 \\
13 & Vanadium & 0.02 \\
14 & Carbon & 0.02 \\
\hline
\end{tabular}

drilling Nimonic C263 alloy under nano fluid mixed MQL environment. Therefore, in the present article comprehensive investigations on the drilling of this metal were carried out under silver nano fluid MQL environment. Optimization of the process parameters to minimise the responses such as thrust force, temperature accumulated near the cutting edge of the drill, flank wear, and roughness were carried out with the help of RSM-Desirability approach.

\section{Materials and methods}

\subsection{Material}

Nimonic C263 alloy specimens of $10 \mathrm{~mm}$ thickness and $70 \mathrm{~mm}$ diameter with a hardness of $32 \mathrm{HRc}$ were used. Nimonic C263 is a material with excellent resistance to high temperature and oxidation due to its nickel, chromium and cobalt content. The Nimonic C263 alloy's chemical compositions are (in Wt \%) given in the Table 1.

\subsection{Drilling conditions}

During machining of this alloy which has high work hardening and also high temperature is generated. Taking into consideration of the abrasive behaviour of the Nickel based Nimonic, it results in high contact surface temperatures between the tool and work piece. Hence, suitable drill material should be selected to machine this alloy which has high hardness. Of the tool materials, AlCrN coated drills is chosen for machining Nimonic C263 alloy as these tool materials possess high strength and high tolerance to plastic deformation and flank wear. Holes were drilled at dry and nano lubricant environment. Drill Signatures of AlCrN Coated Drill as follows: Helix angle- $30^{\circ}$, Coating$\mathrm{AlCrN}$, Material grade $-10 \%$ of cobalt, cutting direction Right Angle, drill diameter- $6 \mathrm{~mm}$, overall length- $60 \mathrm{~mm}$, 
flute length- $25 \mathrm{~mm}$, point angle of drill used- $140^{\circ}$. The process parameters are point angle $(2 \rho)$, feed rate $(f)$, spindle speed $(\mathrm{N})$, weight percentage of nano particle $(\mathrm{Wp}$ in $\%$ ) and coolant pressure $(\mathrm{P})$.

The experimental trails were done on a vertical CNC machining center (VMC 100) and the specification of Drilling Machine is shown in the Table 2. The drilling tests were performed utilizing Silver Nano lubricant under Minimum Quantity Lubricant (MQL) condition. Silver Nano fluid is prepared by use of ultra-sonication process. Silver nano particle is added to the water-based coolant oil and certain amount of sodium hydroxide is used as the stabilizer for the nano particle in the lubricant. Three levels of nano particle concentration in the coolant are used for the machining of this alloy. Under MQL conditions, the lubricant must be forced into the cutting region through the nozzle at high pressure and high speed. The Flow rate of $125 \mathrm{ml} / \mathrm{h}$ was considered during the experiment.

\subsection{Experimental methods and results}

The machining characteristics such as thrust force, temperature at drill cutting edge, surface roughness and flank wear were evaluated by conducting drilling experiments at various levels of process parameters. The four key factors in this experiment are spindle speed, feed rate, and pressure of the coolant and weight percentage of nano particles. The experiments have been designed based on L9 Taguchi's orthogonal array. Table 3 displays the process parameters conditions, their symbols and levels. Surface roughness, thrust force, temperature at drill cutting edged, tool wear and surface integrity were measured using,

Table 2. Specification of drilling machine.

\begin{tabular}{lll}
\hline S. no & Items & Specifications \\
\hline 1 & Voltage & $220 / 380$ \\
2 & X-Y-Z Servo Motors $(\mathrm{W})$ & 750 \\
3 & Spindle Motor (HP) & 5 \\
4 & Tool Mounting & ISO 40 \\
5 & Centre to the table $(\mathrm{mm})$ & IO-450 \\
6 & Axis-X in mm & 1000 \\
7 & Axis-Y in mm & 500 \\
8 & Axis-Z-axis mm & 500 \\
9 & Length (mm) & 2700 \\
10 & Width $(\mathrm{mm})$ & 2500 \\
\hline
\end{tabular}

Talysurf coder, Kistler's three-component piezoelectric dynamometer, pyrometer, and toolmaker microscope and stress analyzer respectively. Utilizing a SEM (Scanning electron microscope), the drilled surface and worn-out drill is characterized. Wire electro-discharge machining (WEDM) is used to cut the drilled work piece into various sections/specimens. These specimens were used to measure the residual stresses induced on the drilled surface. An Xray stress analyser (diffractometer) was used to measure the residual stress at different locations on the sample. A standard stress-free sample was used to calibrate the unit before the residual stress measurements were made. Figure 1 shows the experimental set up. Figure 2 shows the surface residual stress analyser.

\section{Results and discussion}

To preserve and/or improve the aircraft parts reliability, there will be chances for destruction or alterations in the work piece's surface that can occur when the material is machined. Therefore, the present work concentrates on the investigations of the thrust force, temperature at drill cutting edge, surface roughness and flank wear, while drilling this alloy under Nano fluid mixed MQL condition.

\subsection{Process parameter's effect on thrust force}

Figure 3 displays 3Dimensionsl plots of thrust force. These plots were obtained based on RSM at varying the level of 2 parameters and other 2 parameters are kept at middle level. It is seen in these plots, that the thrust force

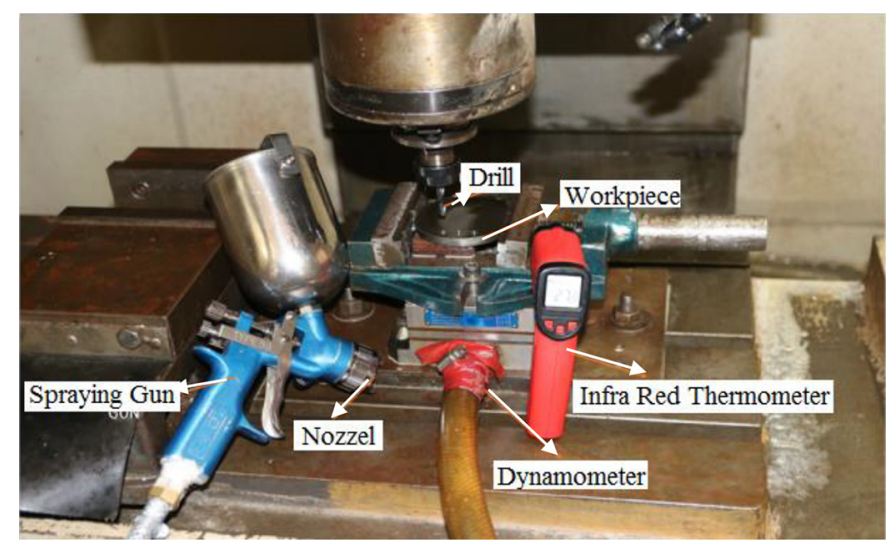

Fig. 1. Equipment Setup Used - Nano fluid mixed MQL condition.

Table 3. Process parameters.

\begin{tabular}{llllll}
\hline S. no & Input parameter & Unit & Level 1 & Level 2 & Level 3 \\
\hline 1 & Speed of the spindle & $\mathrm{rev} / \mathrm{min}$ & 1000 & 1250 & 1500 \\
2 & Feed rate & $\mathrm{mm} / \mathrm{rev}$ & 0.05 & 0.10 & 0.125 \\
3 & Coolant pressure & $\mathrm{P}$ & 250000 & 500000 & 750000 \\
4 & Weight percentage of nanoparticle (\%) & $\mathrm{g}$ & 0.5 & 1 & 1.5 \\
\hline
\end{tabular}



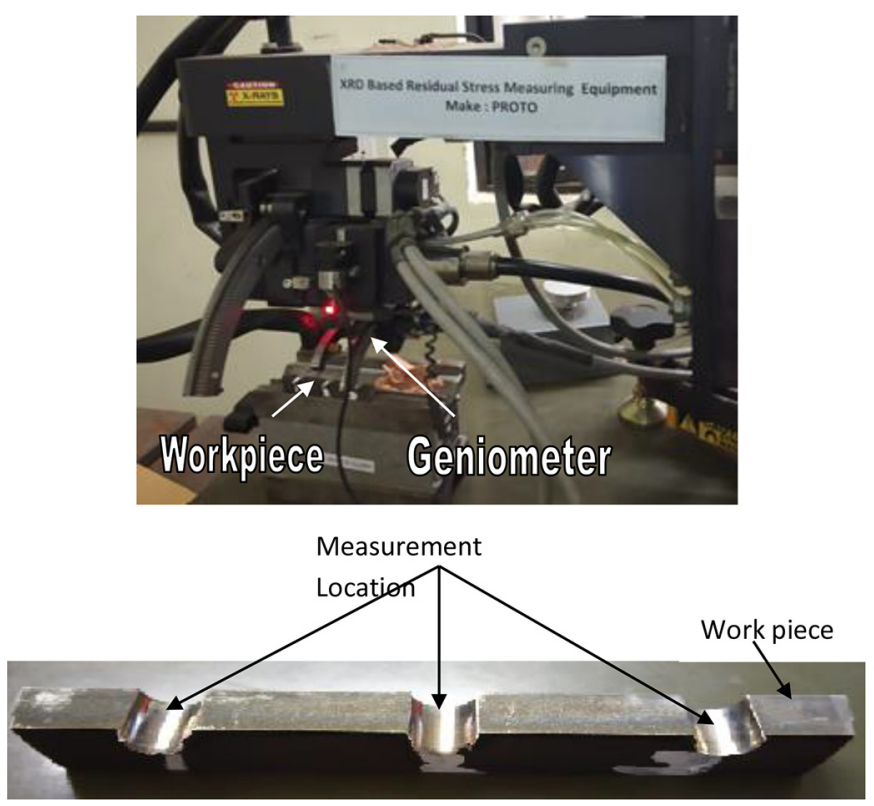

Fig. 2. X-ray Diffraction Stress Analyser.

magnitude is high at low speed of spindle, higher level of feed rate, lower level of nano particle concentration and lower level of coolant pressure. Figure $4 \mathrm{a}$ shows the contour plot in which, the effects of spindle speeds at various feed rates on the thrust force is illustrated by keeping coolant pressure and nano particle concentration at middle level. It is noted that, the thrust force increases at high feed rate and low level speed of the spindle. However, the thrust force value is reduced on increasing the speed of the spindle. It could be due to the higher generation of temperature and associated local softening of work material. The lowest thrust force is measured at a high level of speed of the spindle, low feed rate. The thrust force $(574.113 \mathrm{~N})$ observed at low spindle speed and at high level of high feed rate is 1.21 times higher than the thrust force $(475.209 \mathrm{~N})$ observed at high level of speed of the spindle and at low level of feed rate.

Figure $4 \mathrm{~b}$ exhibited the influence of the speeds of the spindle at various coolant pressure on the thrust force. Higher value of thrust force is observed at low spindle speed and at low coolant pressure. This was owing to that, as the coolant pressure decrease, cooling, lubrication and chip removal abilities of coolant decrease [14]. However, the thrust force value is reduced on increasing the level of the spindle speed and coolant pressure. The lowest thrust force is measured at a high level of the speed of the spindle and coolant pressure in drilling Nimonic C-263 alloy using AlcrN coated drill. When the coolant pressure is increased, more amount of nano scaled nano fluid is entered into the cutting zone and reduce the friction in the cutting zone, thus thrust force is reduced [14]. The thrust force $(559.974 \mathrm{~N})$ measured at low level of spindle speed and coolant pressure is 1.10 times higher than the thrust force $(509.972 \mathrm{~N})$ observed at high spindle speed and coolant pressure.

Figure 4c illustrates the impact of feed rate at various coolant pressure on the thrust force. Higher value of thrust force is noted at higher level of feed rate and coolant pressure. This was due the generation of friction in the cutting zone at high feed rate. However, the thrust force value is reduced on reducing the level of feed rate and coolant pressure. Thus, the impact of feed rate is more than the coolant pressure in drilling for the combination of Nimonic C263 material and AlcrN coated carbide drill. Figure $4 \mathrm{~d}$ exhibits the impact of the spindle speeds at various nano particle concentrations on the thrust force. Higher value of thrust force is noted at lower level of speed of the spindle and nano particle concentration. At lower spindle speed, rubbing in cutting zone would occur, thus thrust force increases. Spindle speed is influenced more on the thrust force than nano particle concentration and the lowest thrust force is witnessed at higher level of speed of the spindle and nano particle concentration level. Figure $4 \mathrm{e}$ illustrates the influence of nano particle concentration at various levels of feed rate on thrust force. Higher value of thrust force is observed at higher level feed rate and nano particle concentration. Lowest thrust force is noted at low feed rate and nano particle concentration. Figure $4 \mathrm{f}$ shows the effect of coolant pressure at various nano particle concentrations on the thrust force. Lower value of thrust force is identified at higher level of coolant pressure and nano particle concentration. This was owing to that, as the coolant pressure increase, cooling, and lubrication increase and also the cutting fluid spreads over large area. The thrust force is increased on reducing the level of nano particle concentration and coolant pressure.

Thus, from the Figure $4 \mathrm{a}-\mathrm{f}$, the lowest thrust force is observed at higher level of spindle speed, lower level of feed rate, higher level of coolant pressure and nano particle concentration. From Figure 4a-f, it is noted that the thrust force tends to vary with the variation of input parameters such as spindle speed, feed rate, coolant pressure and Nano particle concentration. The thrust force increases at lower level speed of the spindle, lower level of coolant pressure and lower level nano particle concentration. It is observed that with the increasing the level of feed, the thrust force increases for all level of spindle speeds, coolant pressure and nano particle concentration. This may be attributed due to that, as the level of feed rate is increased, the greater the thrust is generated and also the material is more sensitive to spindle speed compared to other process parameters.

\subsection{Process parameter's effect on temperature at drill cutting edge}

The 3D plots were obtained based on RSM at varying the level of 2 parameters and other 2 parameters are kept at middle level as seen in the Figure $5 \mathrm{a}-\mathrm{c}$. It is seen in these plots, that the magnitude of the temperature is high at higher level of speed of the spindle, higher level of feed rate, lower level of nano particle concentration and lower level of coolant pressure. Figure 6 a shows the impact of speed of the spindle at various feed rates on temperature at drill cutting edge and it is noted that, the temperature raises at high spindle speed and high feed rate. It would be occurred due the fractured drill cutting edge caused because of the friction at cutting edge and work surface interaction, which 


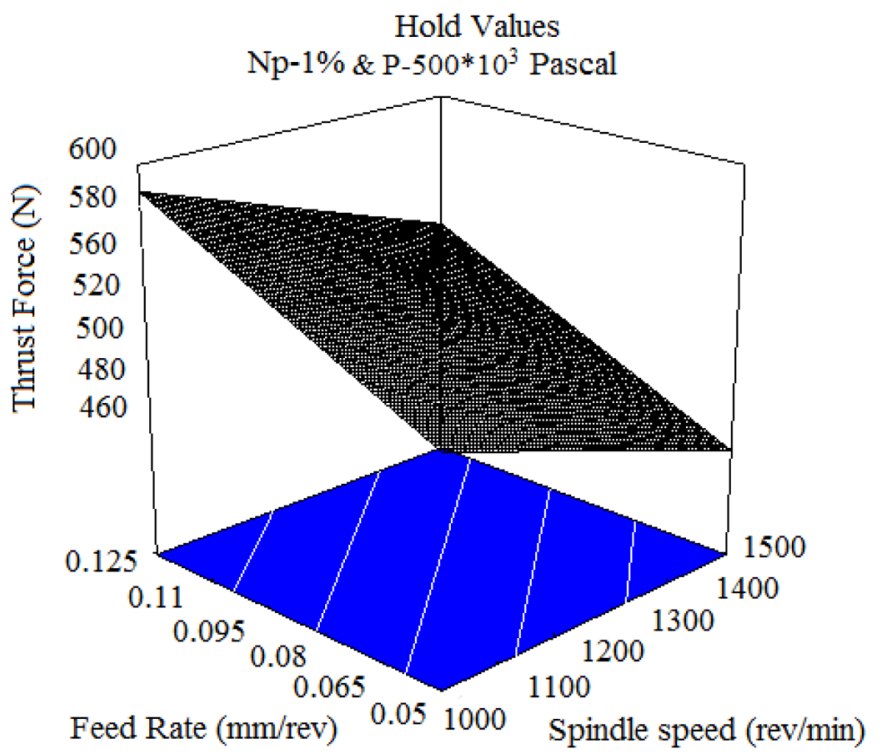

(a)

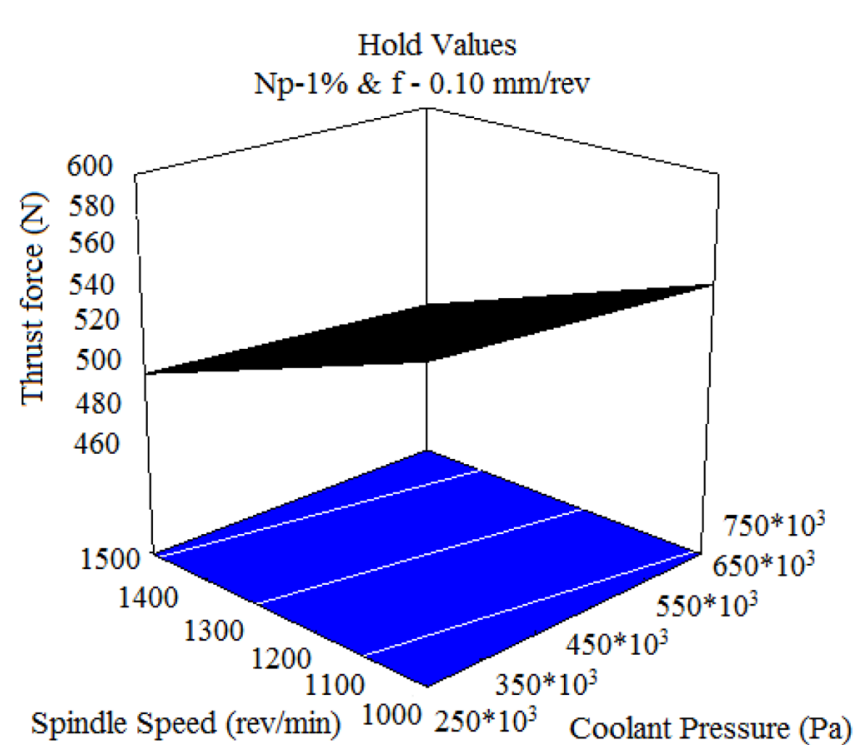

(b)

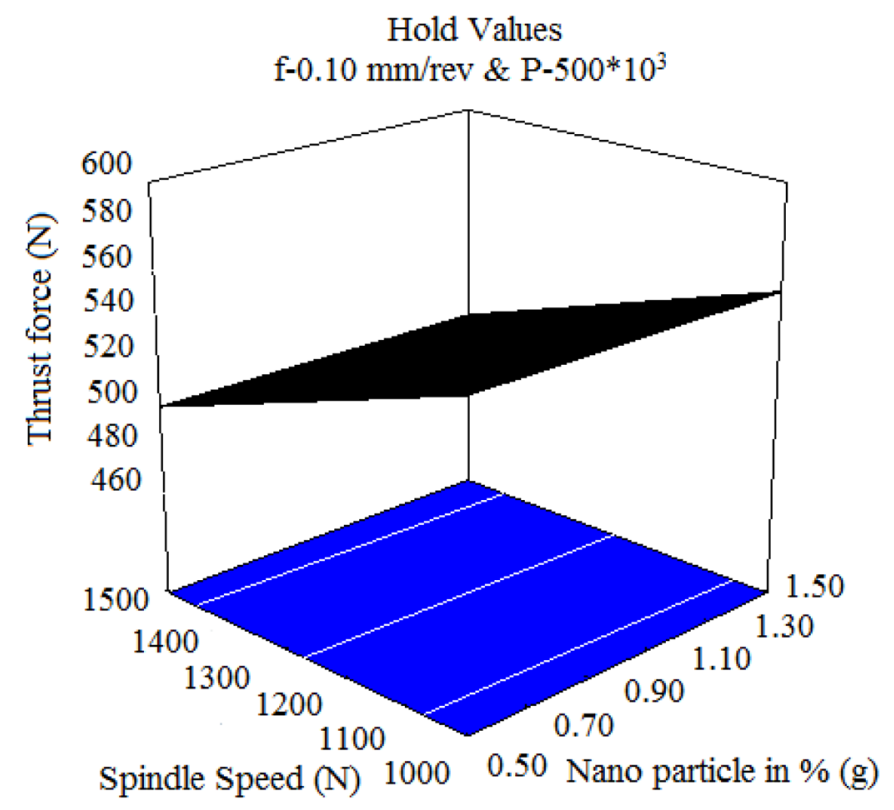

(c)

Fig. 3. (a-c) $3 \mathrm{D}$ plots for the $\mathrm{F}_{\mathrm{z}}$ (a) $3 \mathrm{D}$ plots for $\mathrm{F}_{\mathrm{z}}$ at P-500* $103(\mathrm{~Pa}), \mathrm{Np}-1 \% \mathrm{~g}$ (b) $3 \mathrm{D}$ plots for the $\mathrm{F}_{\mathrm{z}}$ at $\mathrm{f}-0.05$ ( $\left.\mathrm{mm} / \mathrm{rev}\right)$, Np- $1 \%$ (g) (c) $3 \mathrm{D}$ plots for $\mathrm{F}_{\mathrm{z}}$ at $\mathrm{f}-0.050 \mathrm{~mm} / \mathrm{rev}, \mathrm{P}-500 * 10^{3} \mathrm{~Pa}$.

results in high temperatures and increases tool wear. Nimonic C263 material is metallurgically designed for creep resistance especially at higher temperatures and in the flow zone; the stresses are high rate, which induces damage of cutting edge due to the action of shear and compressive stresses acting at high temperature. The lowest temperature is observed at a low level of speed of the spindle, low level of feed rate while drilling Nimonic C263 alloy using $\mathrm{AlCrN}$ Coated Carbide drill. Figure $6 \mathrm{~b}$ exhibits the impact of the spindle speeds at various level of coolant pressure on temperature at drill cutting edge. High temperatures are noted at high level of spindle speed and low level of coolant pressure. However, the lowest temperature is noted at high level of coolant pressure and lower level of spindle speed. The measured temperature $\left(321^{\circ} \mathrm{C}\right)$ at higher level of spindle speed and low level of coolant pressure is 1.34 times higher than the observed temperature $\left(236^{\circ} \mathrm{C}\right)$ at low level of spindle speed and low of coolant pressure. Figure $6 \mathrm{c}$ exhibits the influence of spindle speed cause at various $\mathrm{Np}$ on the temperature. 
(a) Thrust force (N)

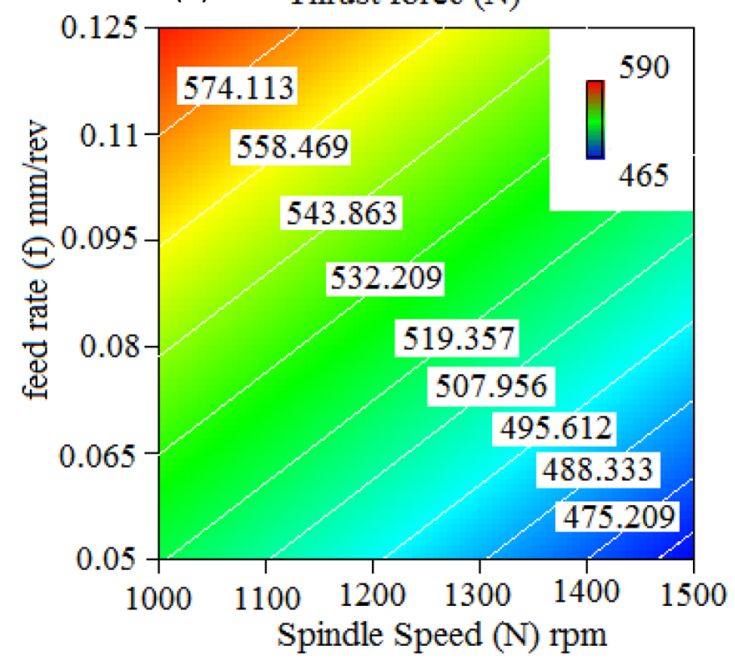

(c) Thrust force (N)

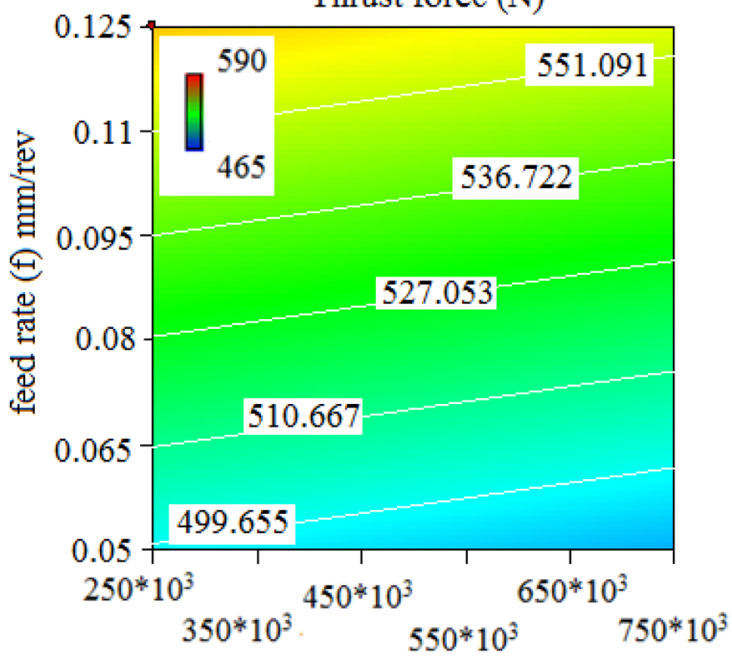

Coolant pressure $(\mathrm{P}) \mathrm{Pa}$

(e)

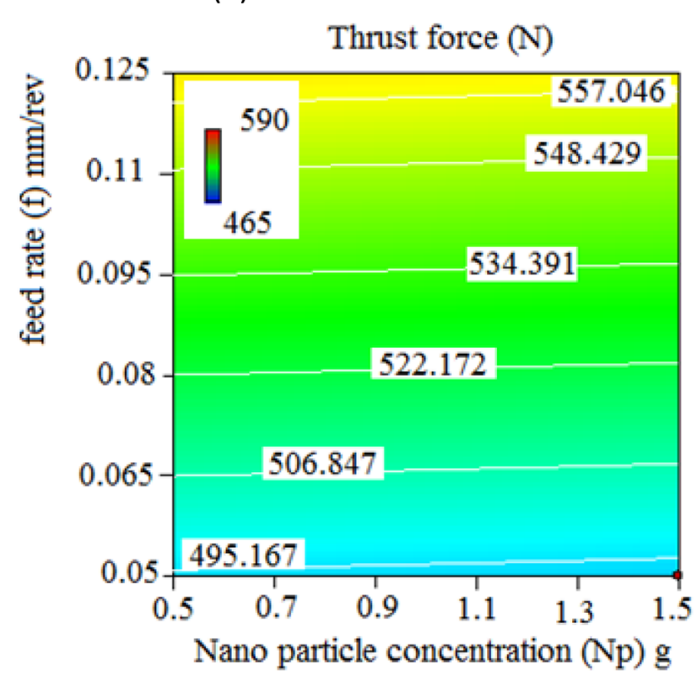

(b) Thrust force (N)

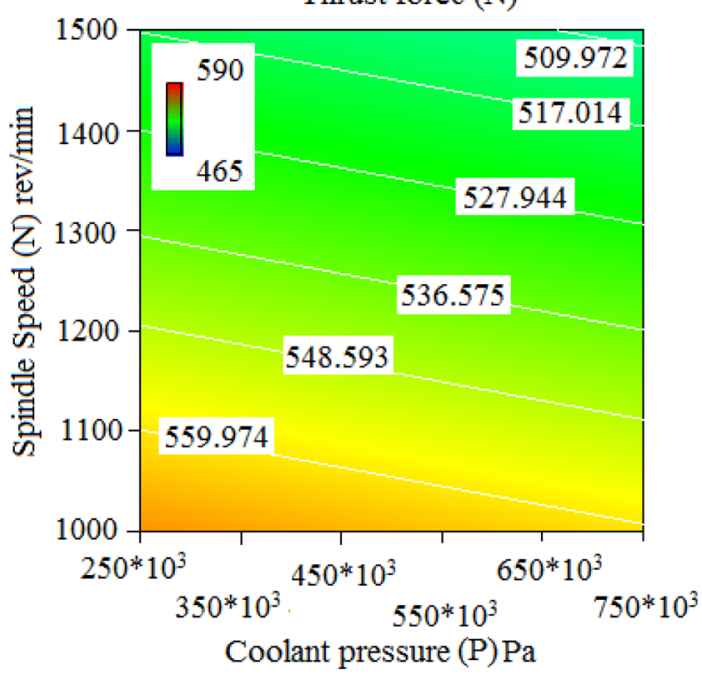

(d) Thrust force (N)

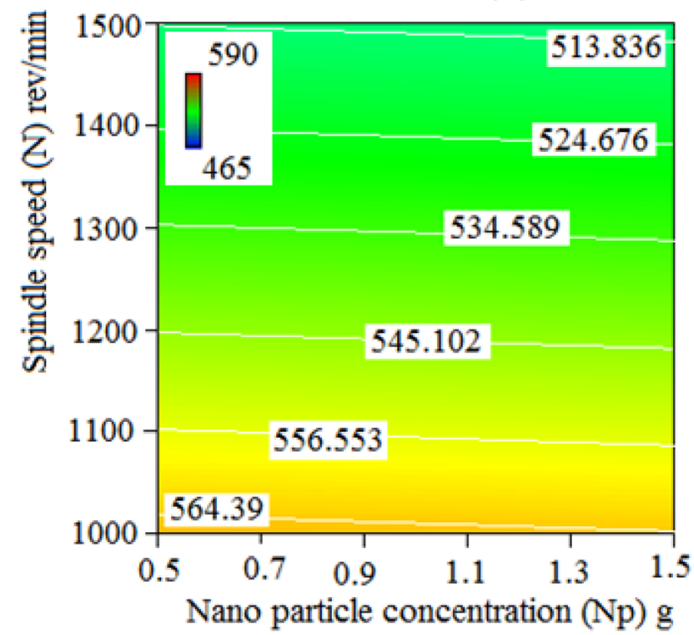

(f) Thrust force (N)

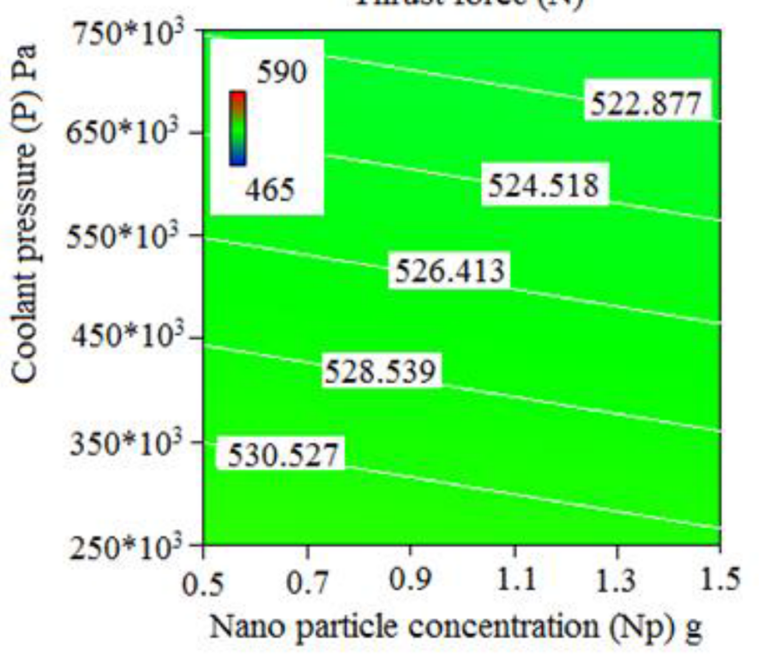

Fig. 4. (a-f) Effects of process parameters on ' $\mathrm{F}_{\mathrm{z}}$ ', (a) effect of ' $\mathrm{N}$ ' at different ' $f$ ', (b) Effect of $\mathrm{N}$ at different 'P', (c) Effect of 'f' at different ' $P$ '. (d) Effect of 'N'at different ' $N_{p}$ '(e) Feed Effect of ' $f$ at different ' $N_{p}$ ', (f) Effect of 'P' at different ' $N_{p}$ '. 


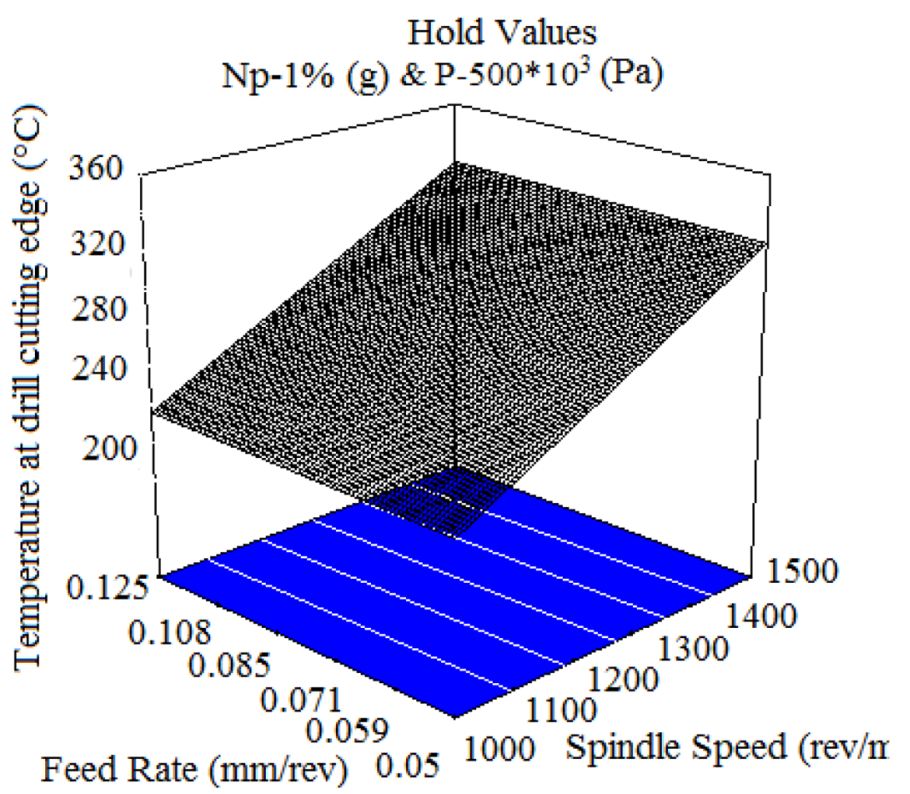

(a)

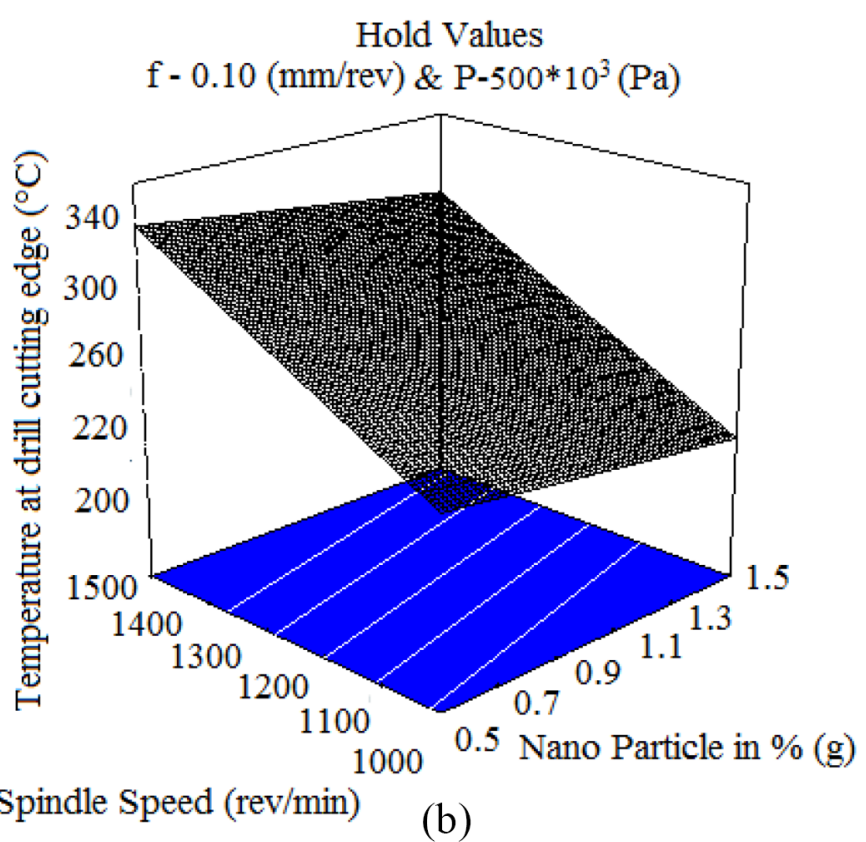

Spindle Speed (rev/min)

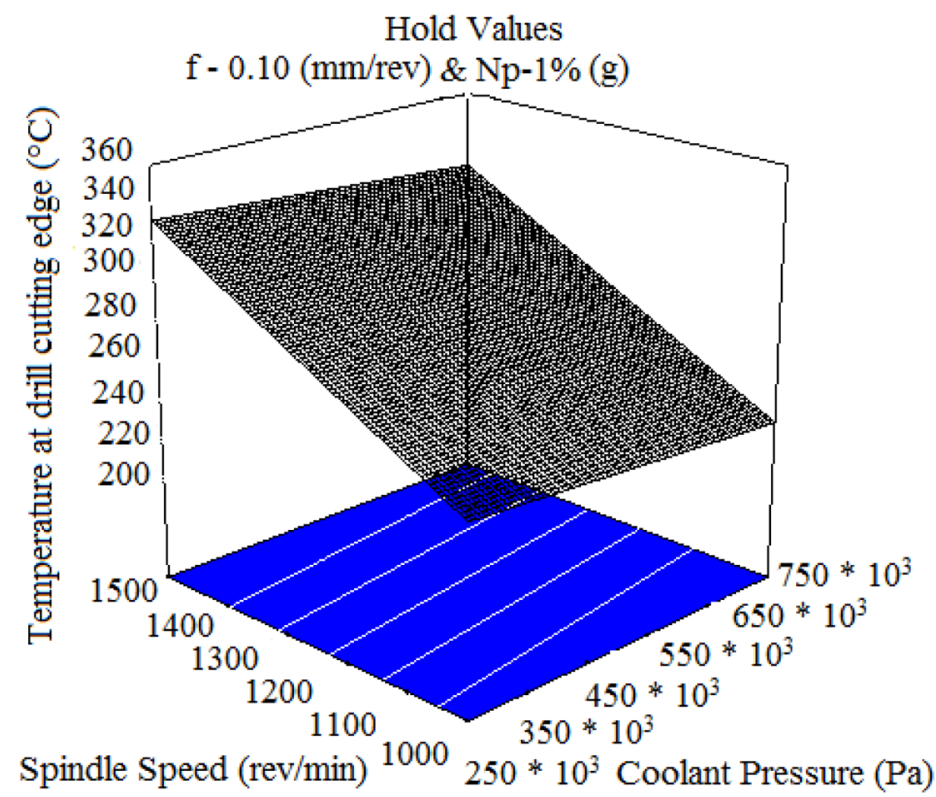

(c)

Fig. 5. (a-c) $3 \mathrm{D}$ plots for $\Theta\left({ }^{\circ} \mathrm{C}\right)$ : (a) $3 \mathrm{D}$ plots for $\Theta\left({ }^{\circ} \mathrm{C}\right)$ at $\mathrm{P}-500^{*} 10^{3}(\mathrm{~Pa}), \mathrm{Np}-1 \%(\mathrm{~g}),(\mathrm{b}) 3 \mathrm{D}$ plots for $\Theta\left({ }^{\circ} \mathrm{C}\right)$ at f- $0.10 \mathrm{~mm} / \mathrm{rev}$, p-500* $10^{3}(\mathrm{~Pa})$, (c) $3 \mathrm{D}$ plots for $\Theta\left({ }^{\circ} \mathrm{C}\right)$ at $\mathrm{f}-0.10 \mathrm{~mm} / \mathrm{rev}, \mathrm{Np}-1 \%(\mathrm{~g})$.

Higher value of temperature is noted at high level of the speed of the spindle and at low level of nano particle concentration. However, lowest temperature is observed at high level of silver nanoparticle concentration and low level of speed of the spindle. The reduction in the temperature at cutting zone was observed, while turning the titanium alloy under silver nano fluid MQL environment [15].

Figure 6d exhibits the impact of feed rate on the temperature at various Np. Higher temperature values are seen at higher feed rate and at low level of nano particles concentration. Nonetheless, the lowest temperature is noted at high level of feed rate and high level of level Np. However, it is noted that, the impact of nano particle concentration plays vital role on reducing the temperature than the feed rate in drilling this Nimonic C263 using AlCrN coated carbide drill. Figure 6e illustrates the influence of the coolant pressure at different level of $\mathrm{Np}$ on temperature at drill cutting edge. At higher level of coolant 


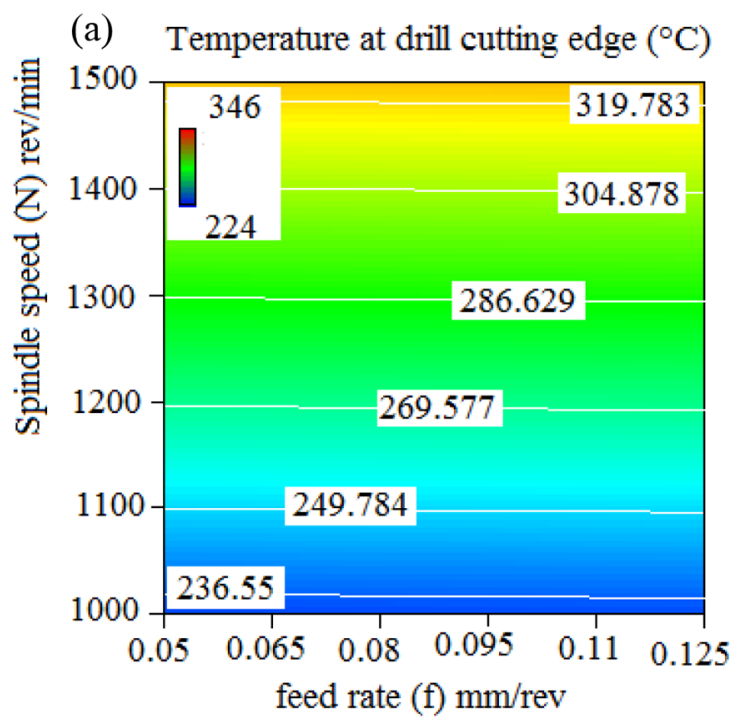

(c)

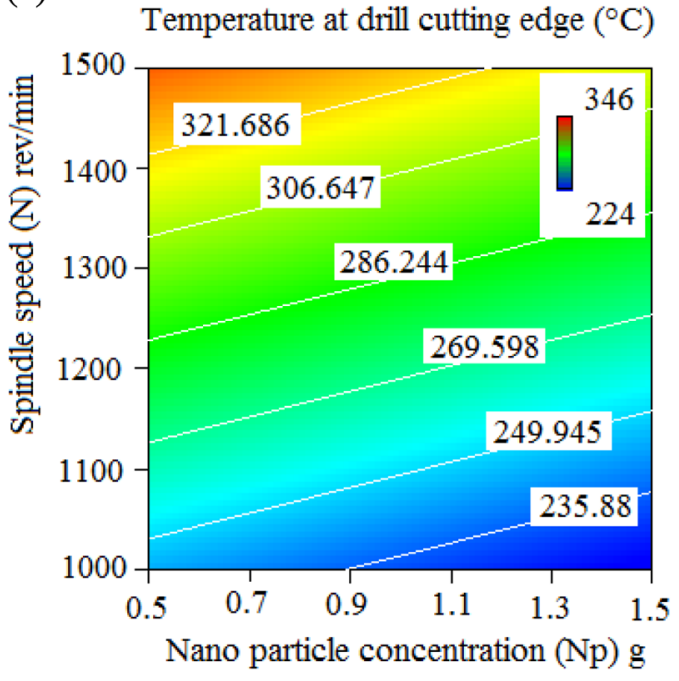

(e) Temperature at drill cutting edge $\left({ }^{\circ} \mathrm{C}\right)$

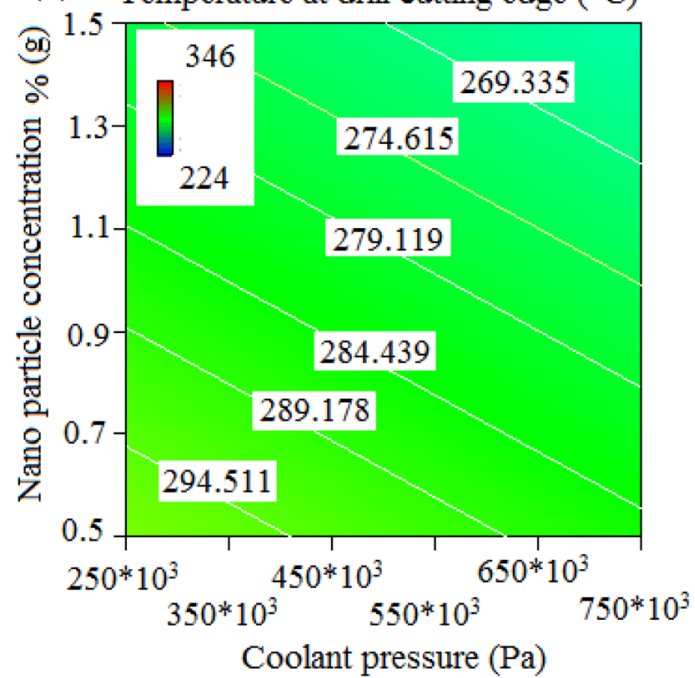

(b) Temperature at drill cutting edge $\left({ }^{\circ} \mathrm{C}\right)$

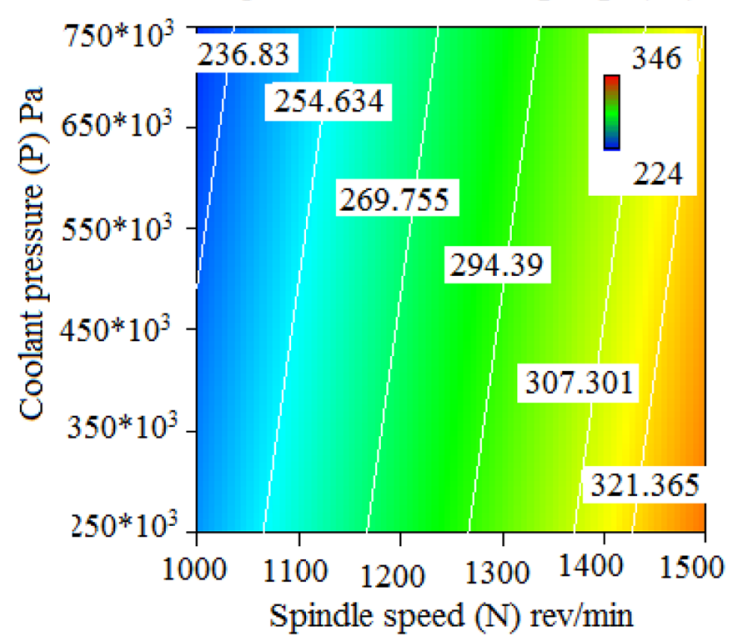

(d) Temperature at drill cutting edge $\left({ }^{\circ} \mathrm{C}\right)$

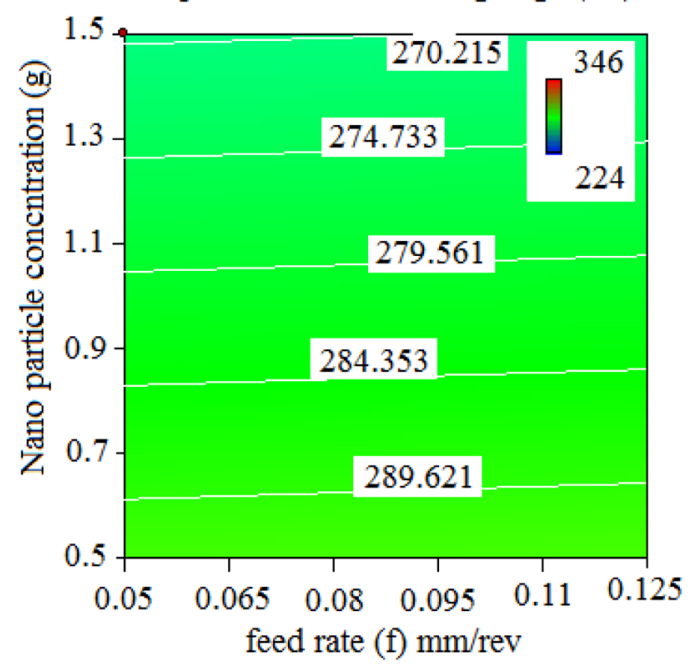

(f) Temperature at drill cutting edge $\left({ }^{\circ} \mathrm{C}\right)$

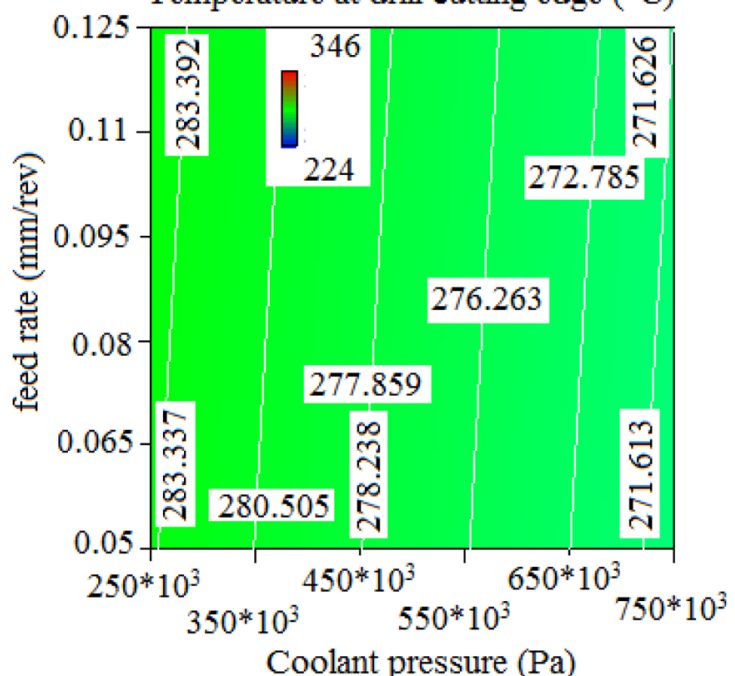

Fig. 6. (a-f) Effect's of process parameters on ' $\Theta$ ', (a) Effect of ' $N$ ' at various ' $f$ on ' $\Theta$ ', (b) Effect of ' $N$ ' at different 'P' on ' $\Theta$ ' (c) Effect of ' $N$ ' at different 'Np'on ' $\Theta$ ' (d) Effect of ' $f$ ' at different 'Np' on ' $\Theta$ ' (e) Effect of 'P' at different 'Np'on ' $\Theta$ ' (f) Effect of 'f'at different 'P' on ' $\Theta$ '. 


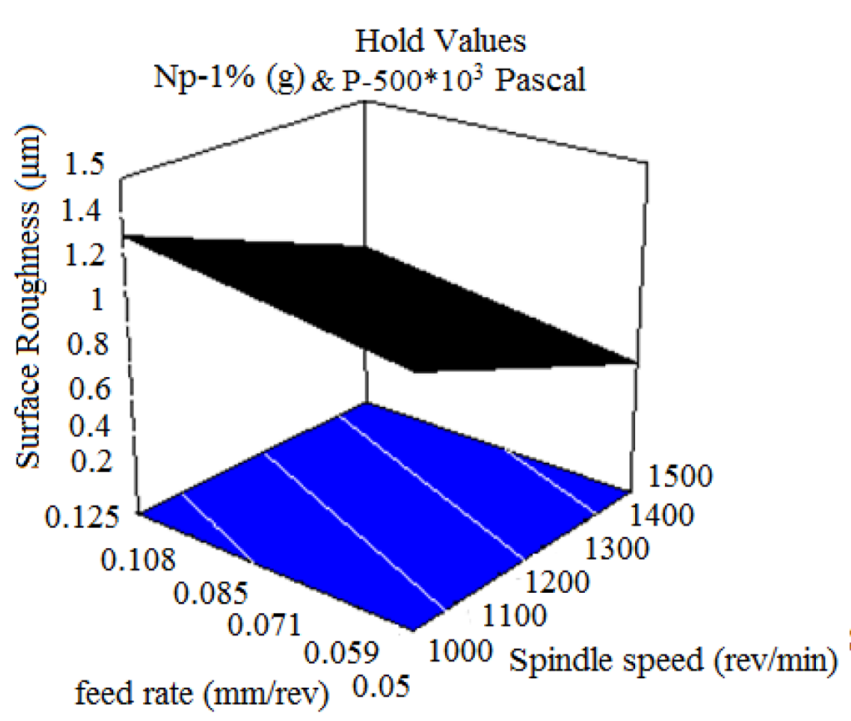

(a)

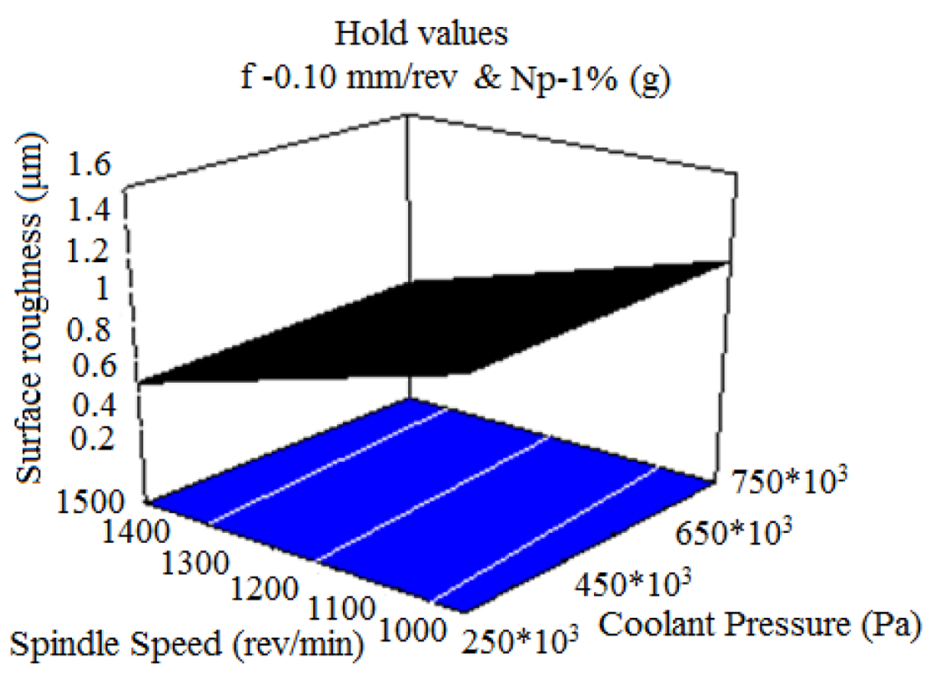

Hold values

(b)

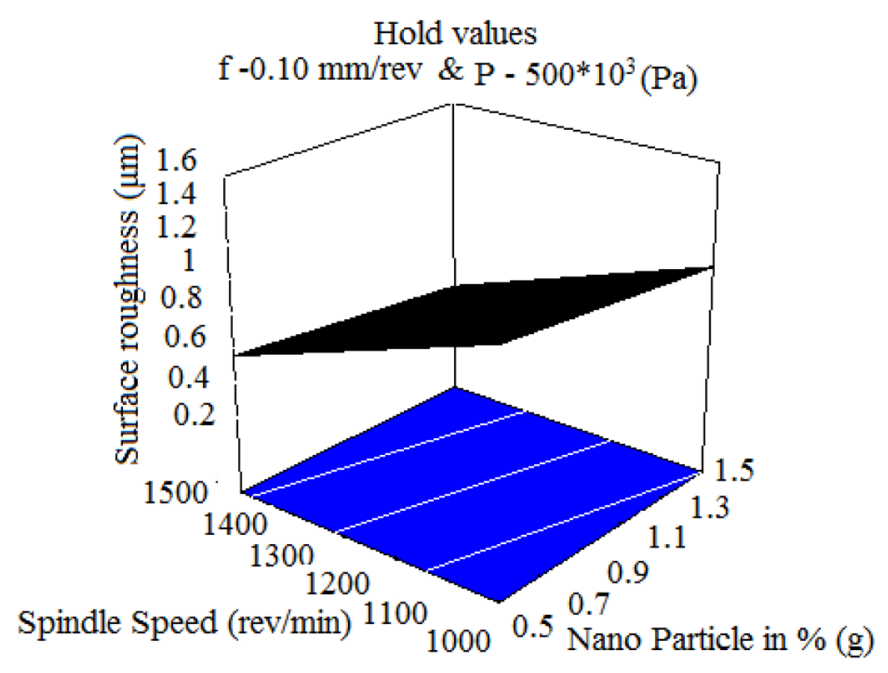

(c)

Fig. 7. (a-c) 3D Plots for $\mathrm{R}_{\mathrm{a}}$ (a) $3 \mathrm{D}$ Plots for $\mathrm{R}_{\mathrm{a}}$ at $\mathrm{Np}-1 \%$ (g) and P- $500^{*} 10^{3}$ (Pa) (b) $3 \mathrm{D}$ Plots for $\mathrm{R}_{\mathrm{a}}$ at $f-0.10 \mathrm{~mm} / \mathrm{rev}$ and $\mathrm{Np}-1 \%$ (g), (c) 3D Plots for $\mathrm{R}_{\mathrm{a}}$ at $\mathrm{f}-0.10 \mathrm{~mm} / \mathrm{rev}$ and P-500* $10^{3}$ (Pa).

pressure and concentration of nano particles, the lowest temperature is noted and the temperature is increased on reducing the level of coolant pressure and nano particle concentration. Figure $6 \mathrm{f}$ exhibits the effect of the feed rate at various levels of coolant pressures on the temperature at drill cutting edge. High temperature is seen at higher feed rate and low level of coolant pressure. Nonetheless, lowest temperature is noted at low level of feed rate and high level of coolant pressure. Thus, the temperature at drill cutting edge is influenced by spindle speed followed by nano particle concentration, coolant pressure and feed rate. It would be occurred due to that, the drill cutting edge would be fractured due to friction between the cutting edge and the work surface, which causes high temperatures as well as, when the level of nano concentration is reduced, the wettability and heat transfer is also reduced.

\subsection{Process parameter's effect on surface roughness}

The 3Dimensional plots for surface roughness are illustrated in Figure $7 \mathrm{a}-\mathrm{c}$. Using the established RSM model, these plots were obtained based on RSM at varying the level of 2 parameters and other 2 parameters are kept at middle level. It is seen in these plots, that the surface roughness is high at higher level of feed rate, lower level of speed of the spindle, lower level of nano particles concentration and lower level of coolant pressure. Surface finish is an important characteristic in machining to test the quality of the machined object. It is mainly regulated by the feed rate along with the speed of the spindle, in the hole making operations. Figure 8a shows the impact of speed of the spindle on surface roughness at varying feed rate and it is observed that the surface roughness increases at high feed 
(a)

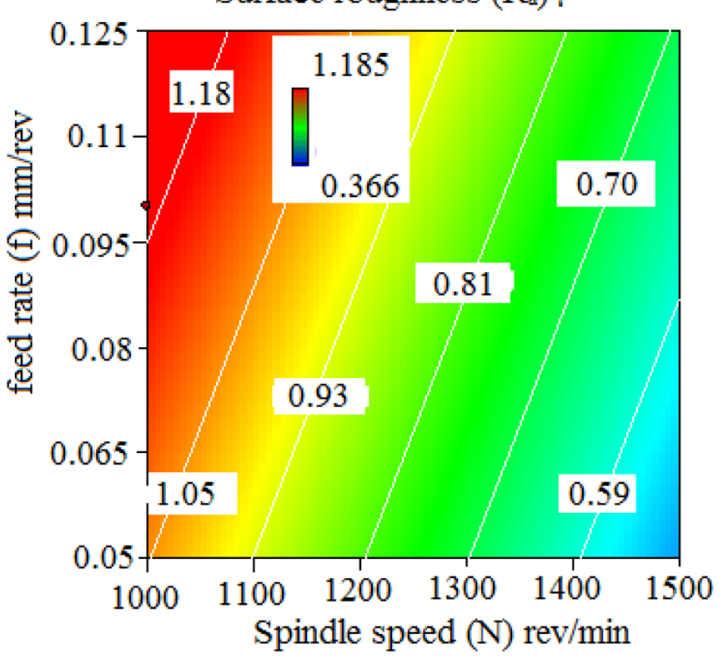

(c)

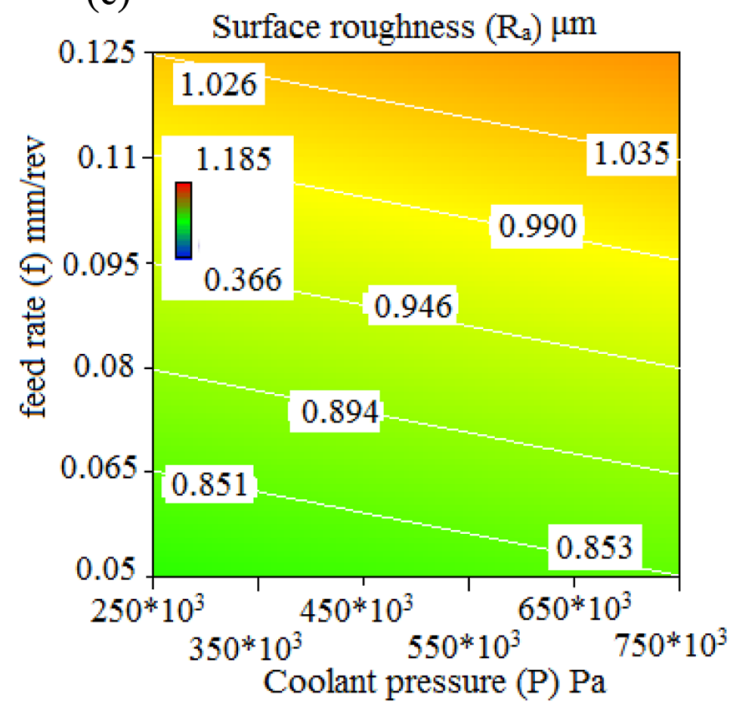

(e)

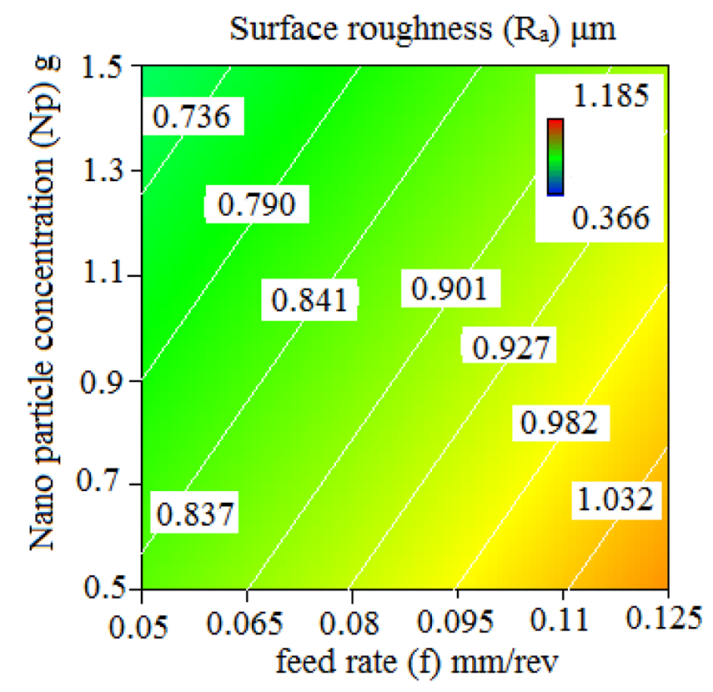

(b)

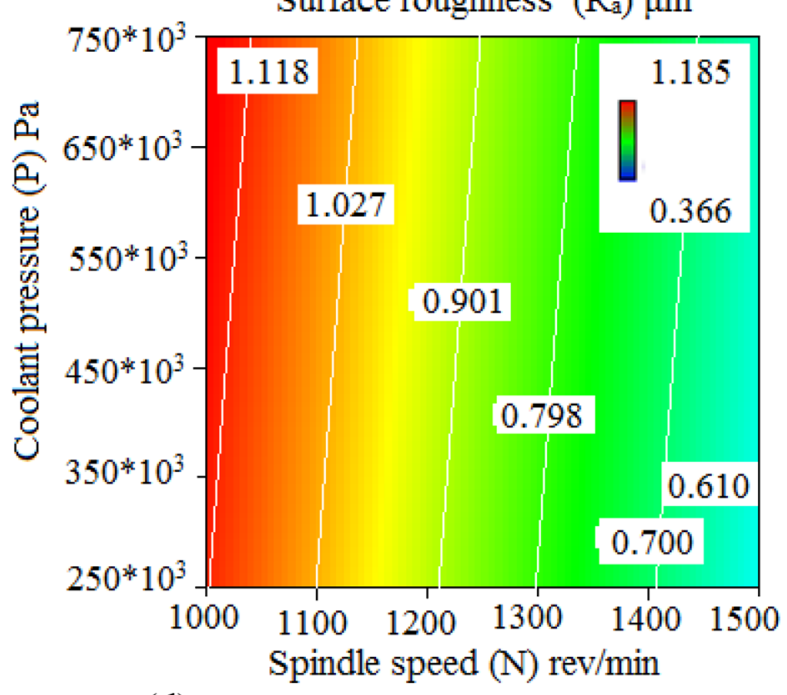

(d)

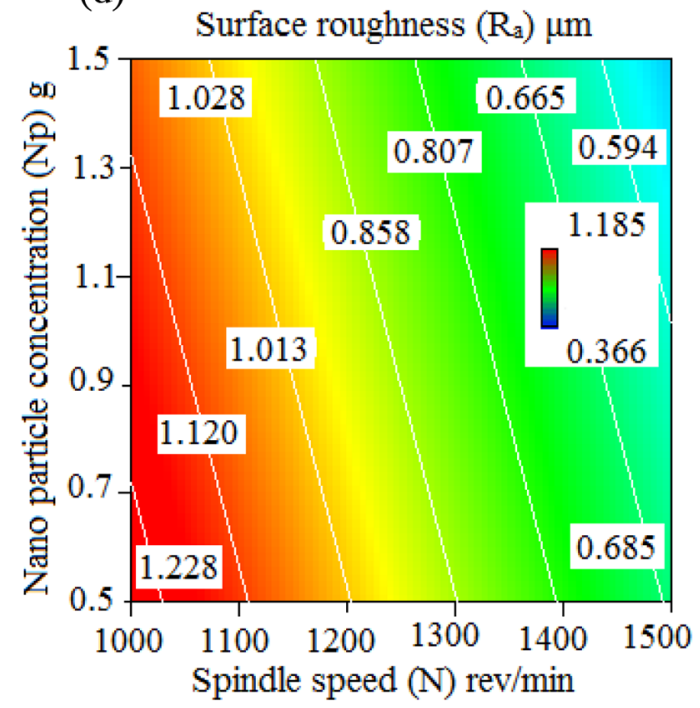

(f)

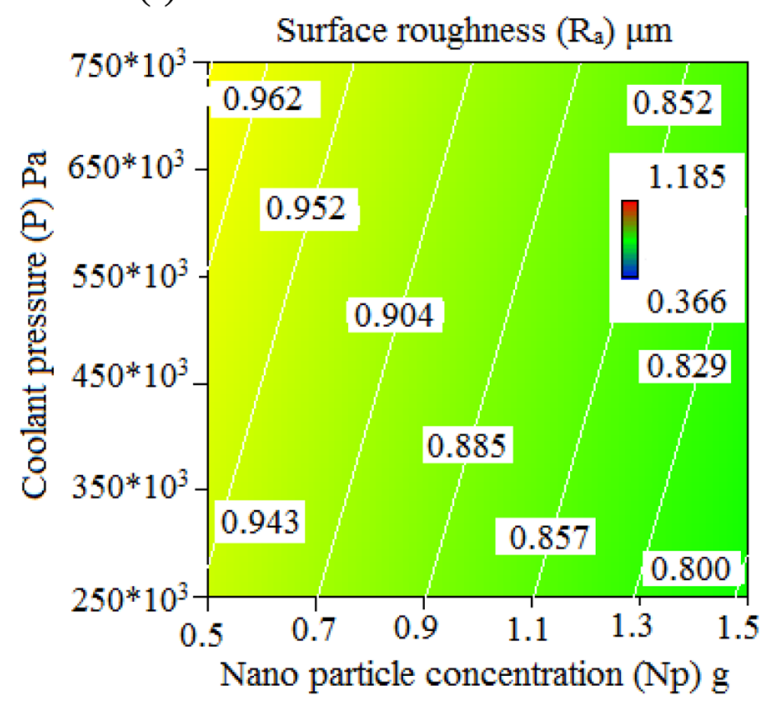

Fig. 8. (a-f) Effect of Process Parameters on ' $R_{a}$ ' (a) Effect of ' $N$ ' at different level of 'f' on ' $R_{a}$ ' (b) Effect of ' $N$ ' at different level of 'P' on ' $R_{a}$ ' (c) Effect of 'f' at different level of ' $P$ ' on ' $R_{a}$ ' (d) Effect of ' $N$ ' at different level of ' $N_{p}$ ' on ' $R_{a}$ ' (e) Effect of ' $f$ ' at different level of ' $N_{p}$ ' on ' $R_{a}$ ' ( $f$ ) effect of ' $P$ ' at different level of ' $N_{p}$ ' on ' $R_{a}$ '. 

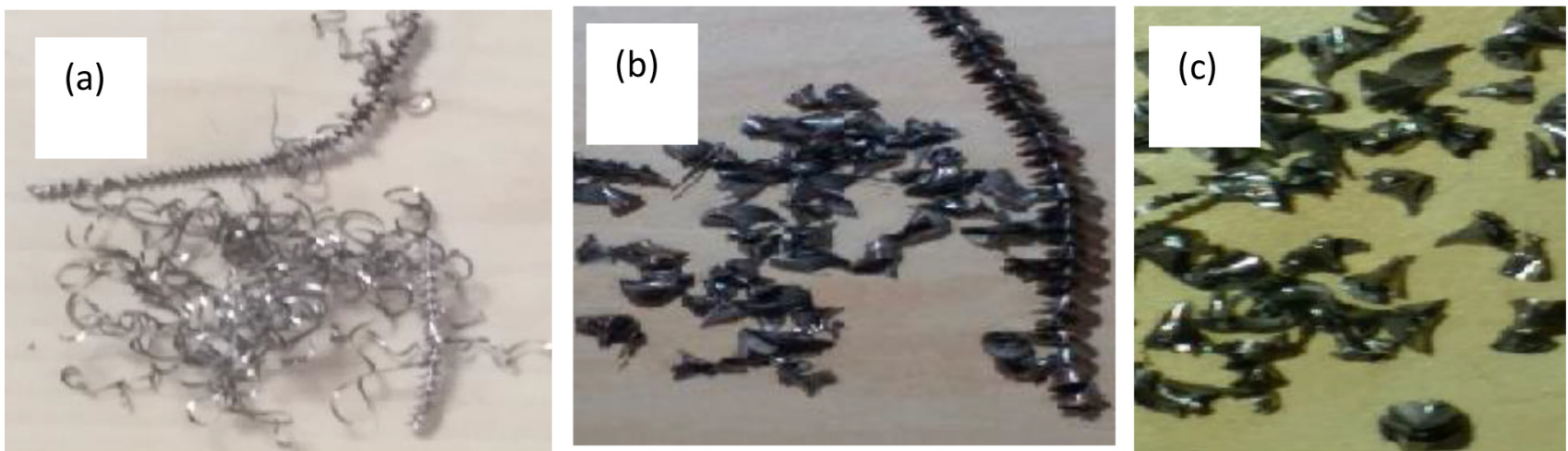

Fig. 9. (a-c) Chips generated at (a) $\mathrm{N}=1500 \mathrm{rpm}, \mathrm{f}=0.05 \mathrm{~mm} / \mathrm{rev}, \mathrm{P}=750^{*} 10^{3} \mathrm{~Pa}, \mathrm{~Np}(\%)=1.5 \quad(\mathrm{~g}),(\mathrm{b}) \mathrm{N}=1250 \mathrm{rpm}$, $\mathrm{f}=0.125 \mathrm{~mm} / \mathrm{rev}, \mathrm{P}=750^{*} 10^{3} \mathrm{~Pa}, \mathrm{~Np}=0.5 \%(\mathrm{~g}),(\mathrm{c}) \mathrm{N}=1500 \mathrm{rpm}, \mathrm{f}=0.125 \mathrm{~mm} / \mathrm{rev}, \mathrm{P}=500^{*} 10^{3}(\mathrm{~Pa}), \mathrm{Np}(\%)=0.5(\mathrm{~g})$.

rate and low spindle speed. Nonetheless, as the spindle speed is increased, the surface roughness decreases. It could be due to higher temperature generation and associated local softening of work material at high level of spindle speed. The lowest surface roughness is obtained at a high level of spindle speed, low and medium level of feed rate. At low spindle speed and high feed rate $(\mathrm{Ra}-1.185 \mu \mathrm{m})$, the surface roughness measured is 2 times greater than the surface roughness observed at high spindle speed and low feed rate $(\mathrm{Ra}-0.59 \mu \mathrm{m})$. Figure $8 \mathrm{~b}$ illustrates the effect of spindle speeds at different pressure on surface roughness. At low spindle speed and high coolant pressure, higher surface roughness is observed. Nevertheless, the roughness of the surface is minimized on increasing the spindle speed and coolant pressure.

Figure $8 \mathrm{c}$ illustrates the impact of the feed rate at different coolant pressure on surface roughness. At higher level of feed rate and coolant pressure, a higher surface roughness value is observed. However, at lower level of feed rate and higher level of coolant pressure, the surface roughness is low. The reduction in the surface roughness was also observed, while turning the titanium alloy under silver nano fluid MQL environment [15]. Figure 8d exhibits the influence of the spindle speeds at different concentrations of nano particles on surface finish. At low spindle speed and higher nano particle concentration, a lower surface roughness value is seen, when compare to the surface roughness observed at low level of spindle speed and low level of nano particle concentration. It would be due to that, an addition of nanoparticle ratio increases the wettability of the nanocutting fluid also the cutting fluid spreads over a larger area on the tool-chip surface [16]. Further, it is seen that, the lowest surface roughness is observed at high level of spindle speed and nano particle concentration $(0.594 \mu \mathrm{m})$. Spindle speed is influenced significantly on surface roughness than nano particle concentration.

Figure 8e illustrates the effect of the of nano particles concentration on surface roughness at various level of feed rate. Higher surface roughness values are observed at higher level of feed rate and concentration of nano particles. Surface finish observed at low feed rate and low level of concentration of nano particles is good. Figure $8 \mathrm{f}$ exhibits the impact of the coolant pressure at different concentrations of nano particles on surface roughness. A higher surface roughness value is observed at a high level of coolant pressure and low level of concentration of nano particles. The surface roughness decreases rapidly at high level of nano particle concentration and low level of coolant pressure, however, the surface roughness reduces as the level of coolant pressure and nano particle concentration increases in drilling this Nimonic C263 using AlCrN coated carbide drill.

Thus, the surface roughness increases with increase in the level of feed rate for all level of speed of the spindle. This may be attributed to higher feed rate; the ridge height (roughness) is increased, thereby leading to higher surface roughness. In addition to the influence of the feed rate and cutting edge geometry, the surface roughness of the machined surface is also influenced by the chip formation process, which includes the properties of the metal being machined and the elastic and plastic deformation of the layers. Figure 9a-c shows the chip generated during drilling at various level of input parameters, in which it is observed that, the built up edge is produced at higher level of spindle speed, lower feed rate, high pressure and high nano concentration and the corresponding roughness values also reduced. The segmental chips were observed at the higher feed rate, medium pressure, low Np concentration and high spindle speed and thus roughness is increased. Figure 10a-i exhibits the Scanning Electron Micrographs of the machined surface obtained at different level of speed of the spindle, feed, nano concentration and coolant pressure. In terms of smeared surface, feed markings, chip fragments, rough surface, smooth surface, etc., the state of the machined surface is shown. From these images it is evident that the surface roughness is high at lower level of speed of the spindle, higher level of feed rate, lower level of concentration of nano particles and lower level of coolant pressure.

\subsection{Process parameter's effect on flank wear}

Figure $11 \mathrm{a}-\mathrm{c}$ shows the 3Dimensional response surface plots for the flank wear. These plots were obtained based on RSM at varying the level of 2 parameters and other 2 parameters are kept at middle level. It can be inferred that the rate of flank wear is higher at higher level of speed of the 

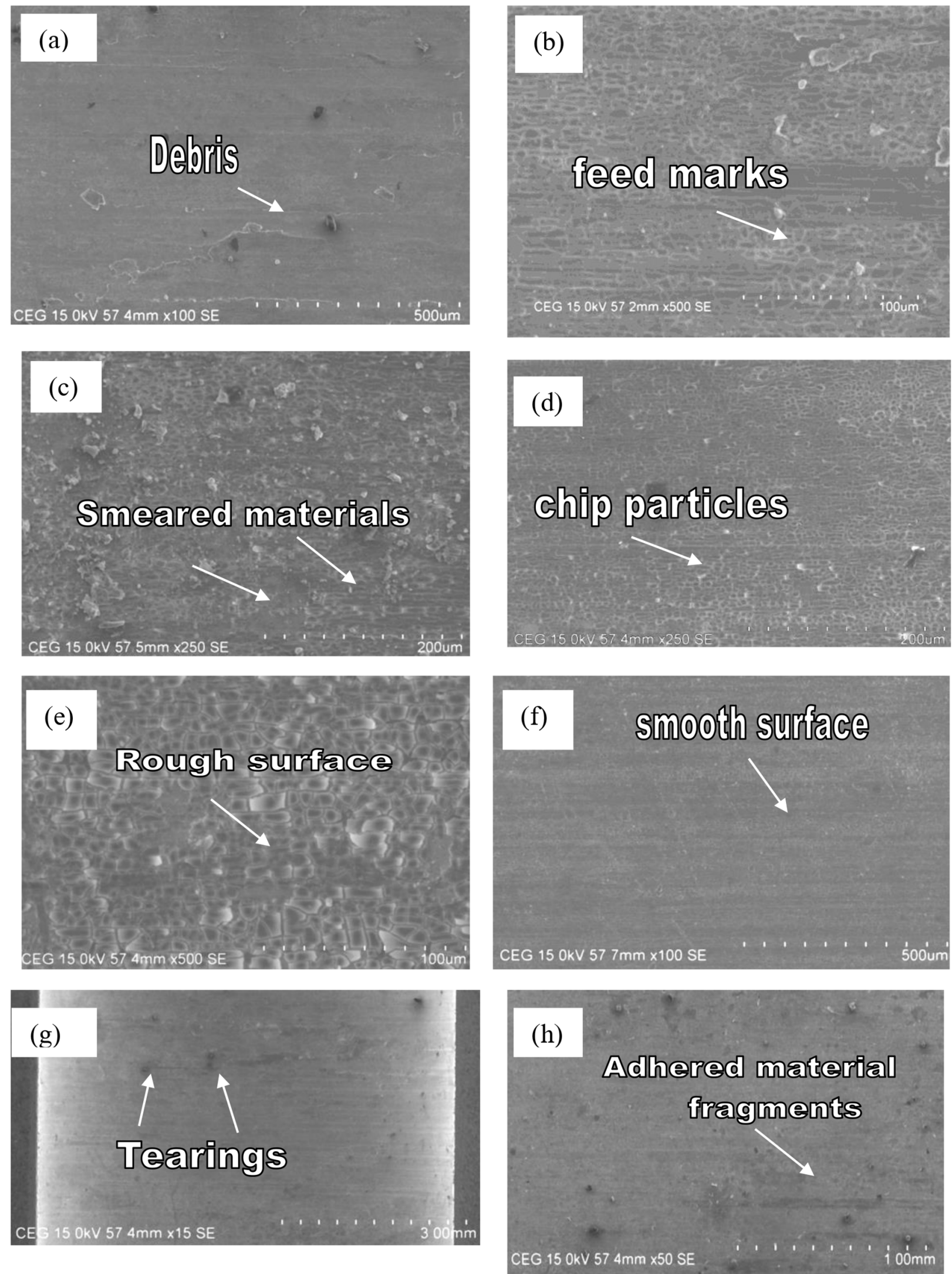

Fig. 10. (a-h) SEM Images of drilled surface at (a) $\mathrm{N}=1000 \mathrm{rpm}, \mathrm{f}=0.05 \mathrm{~mm} / \mathrm{rev}, \mathrm{P}=250^{*} 10^{3}(\mathrm{~Pa}), \mathrm{NP}=0.5(\mathrm{~g}),(\mathrm{b})$. $\mathrm{N}=1000 \mathrm{rpm}$, $\mathrm{f}=0.10 \mathrm{~mm} / \mathrm{rev}, \mathrm{P}=500^{*} 10^{3}(\mathrm{~Pa}), \mathrm{NP}=1 \% \quad(\mathrm{~g}), \quad(\mathrm{c}) \quad \mathrm{N}=1000 \mathrm{rpm}, \mathrm{f}=0.125 \mathrm{~mm} / \mathrm{rev}, \quad \mathrm{P}=750^{*} \quad 10^{3} \quad(\mathrm{~Pa}), \quad \mathrm{NP}=1.5 \quad(\mathrm{~g})$, (d) $\mathrm{N}=1250 \mathrm{rpm}, \mathrm{f}=0.05 \mathrm{~mm} / \mathrm{rev}, \mathrm{P}=500^{*} 10^{3}(\mathrm{~Pa}), \mathrm{NP}=1.5 \quad$ (g) $\quad$ (e) $\mathrm{N}=1250 \mathrm{rpm}, \mathrm{f}=0.10 \mathrm{~mm} / \mathrm{rev}, \mathrm{P}=7500^{*} 10^{3} \mathrm{~Pa}$, $\mathrm{NP}=0.5 \%$ (g) (f) $\mathrm{N}=1500 \mathrm{rpm}, \mathrm{f}=0.05 \mathrm{~mm} / \mathrm{rev}, \mathrm{P}=750^{*} 10^{3}(\mathrm{~Pa}), \mathrm{NP}=1 \%(\mathrm{~g})(\mathrm{h}) \mathrm{N}=1500 \mathrm{rpm}, \mathrm{f}=0.10 \mathrm{~mm} / \mathrm{rev}, \mathrm{P}=250^{*}$ $10^{3}(\mathrm{~Pa}), \mathrm{NP}=1.5 \%(\mathrm{~g})$. 


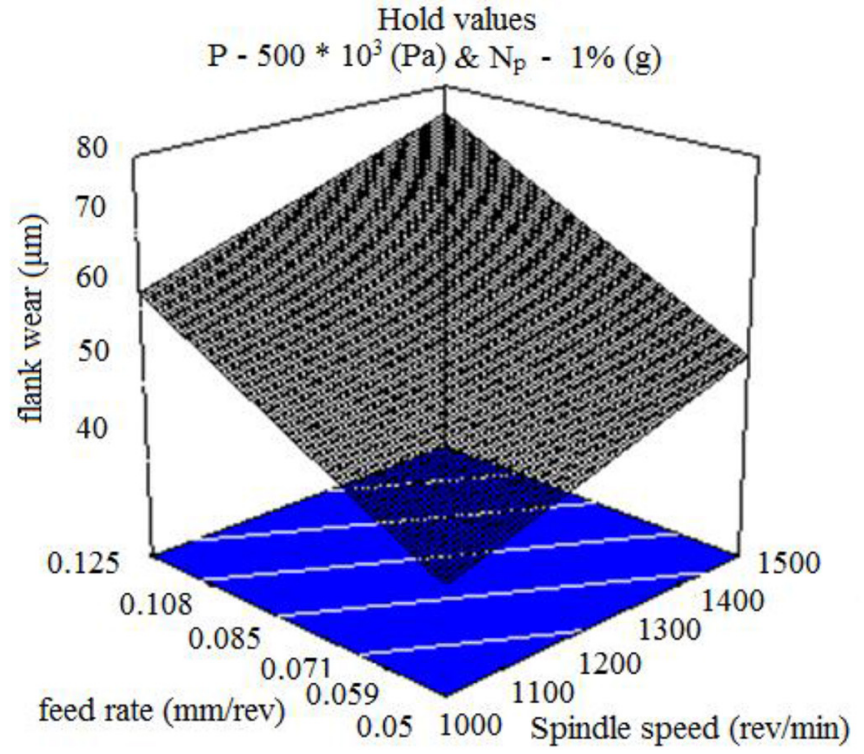

(a)

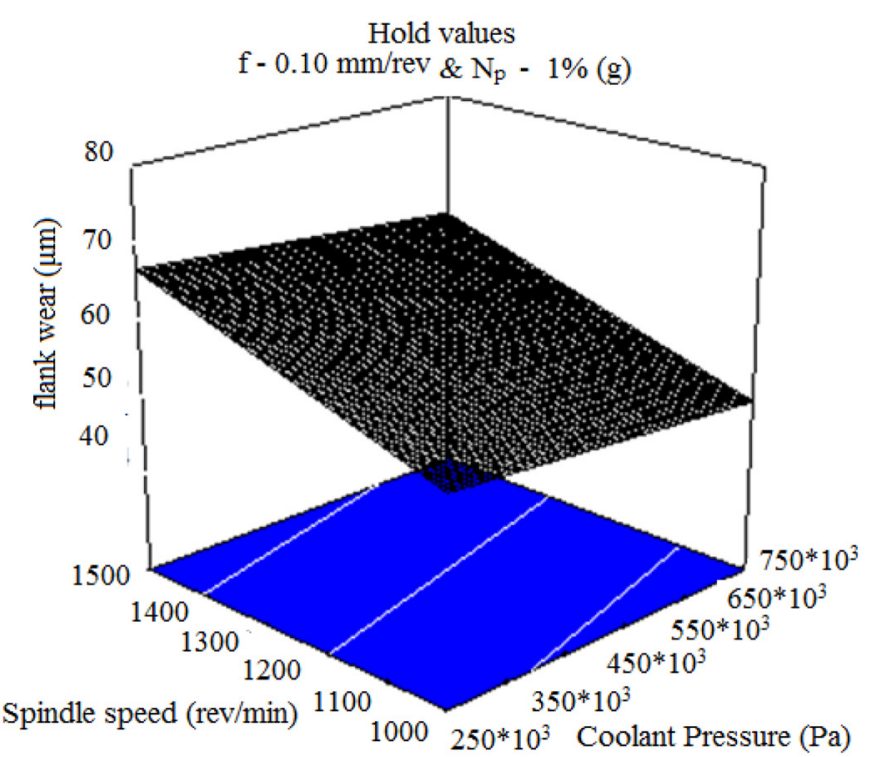

(b)

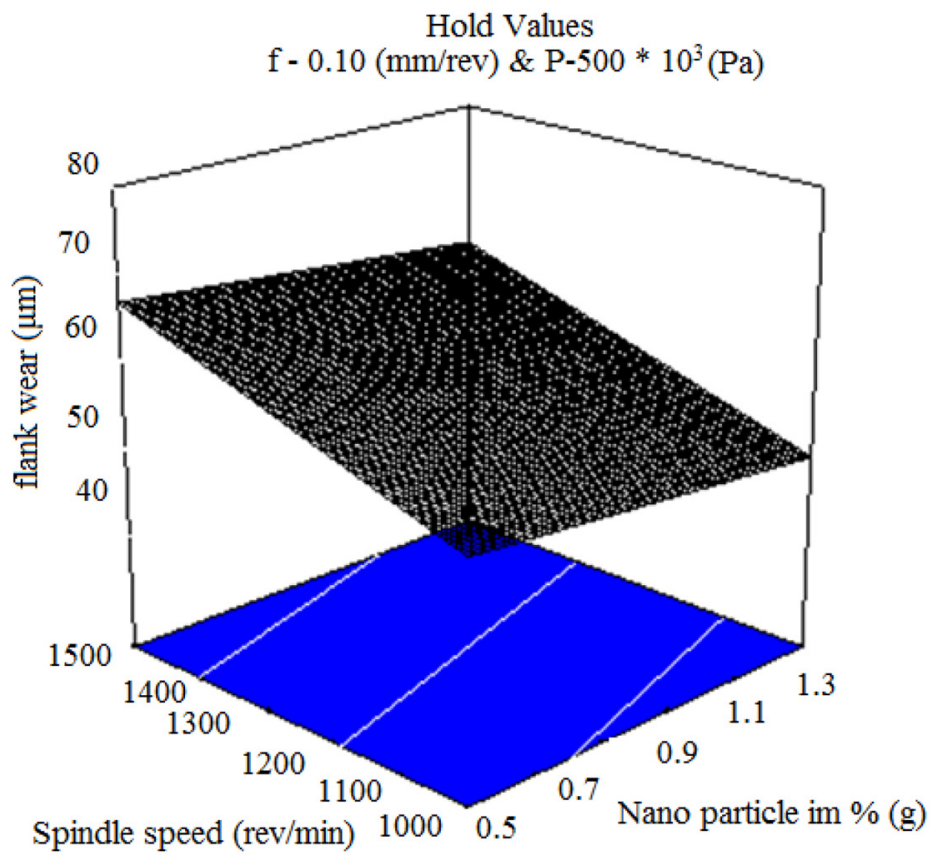

(c)

Fig. 11. (a-c) $3 \mathrm{D}$ plots for $\mathrm{VB}$ (a) $3 \mathrm{D}$ plots for $\mathrm{VB}$ at $\mathrm{P}-500^{*} 10^{3}$ and $\mathrm{Np}-1 \%$ (g), (b) $3 \mathrm{D}$ plots for $\mathrm{VB}$ at $\mathrm{P}-500^{*} 10^{3}$ and $\mathrm{Np}-1 \%$ (g), (c) $3 \mathrm{D}$ plots for $\mathrm{VB}$ at $\mathrm{N}-1250 \mathrm{rev} / \mathrm{min}$ and $\mathrm{Np}-1 \%(\mathrm{~g})$.

spindle, higher level of feed rate, lower level of nano particle concentration and lower level of coolant pressure. Figure 12a illustrates the effect of spindle speeds at various feed rates on the flank wear, and it is noted that flank wear increases at higher level of feed rate and higher level of speed of the spindle. As a consequence, the drill cutting edge would fracture because of the friction between the drill cutting edge and the work piece surface, which produces more temperatures and increases the wear of the tool.
Nimonic C-263 material is metallurgically engineered for creep resistance; the stresses are more in the flow zone, resulting in the degradation of the cutting edge under the pressure of shear and compressive stresses acting at high temperatures. The lowest flank wear is obtained in at lower level of speed of the spindle, and lower level of feed rate.

Figure $12 \mathrm{~b}$ exhibits the effect of spindle speed at different coolant pressures on the flank wear. At higher level of spindle speed and lower level of coolant pressure, 
(a) flank wear (VB) $\mu \mathrm{m}$
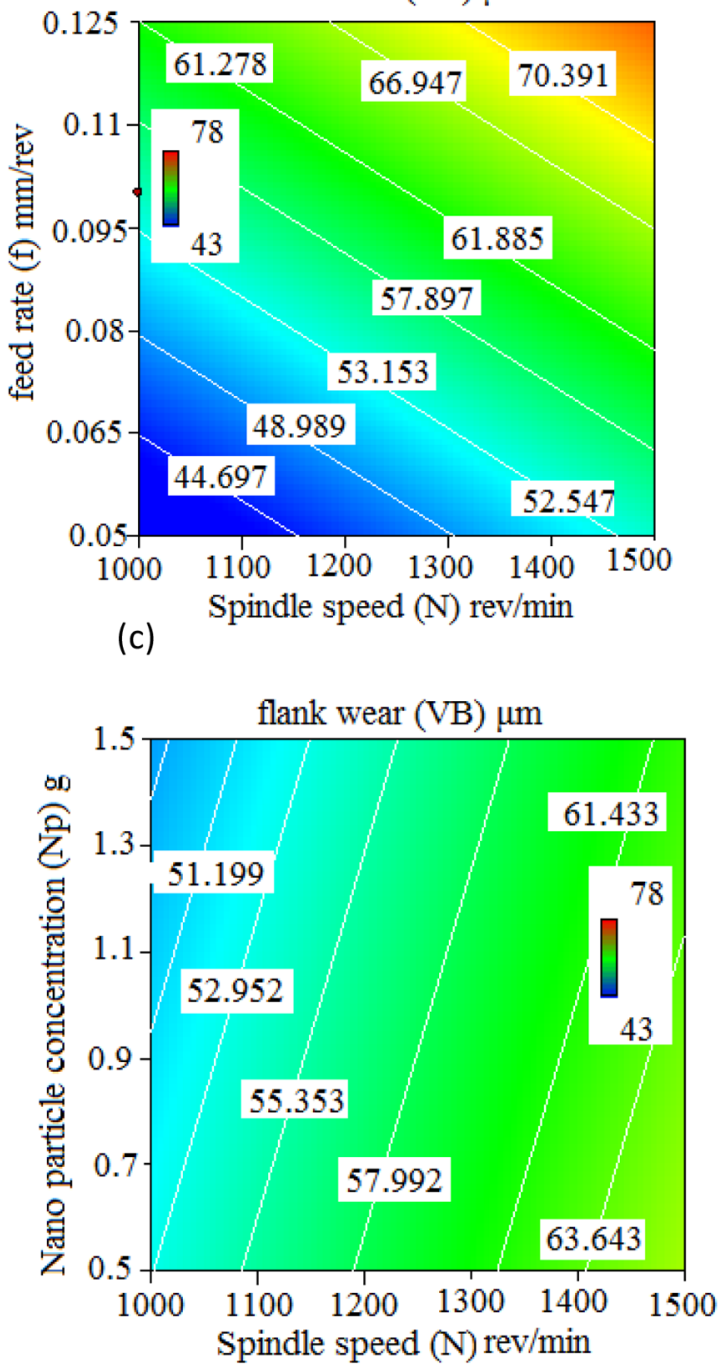

(e)

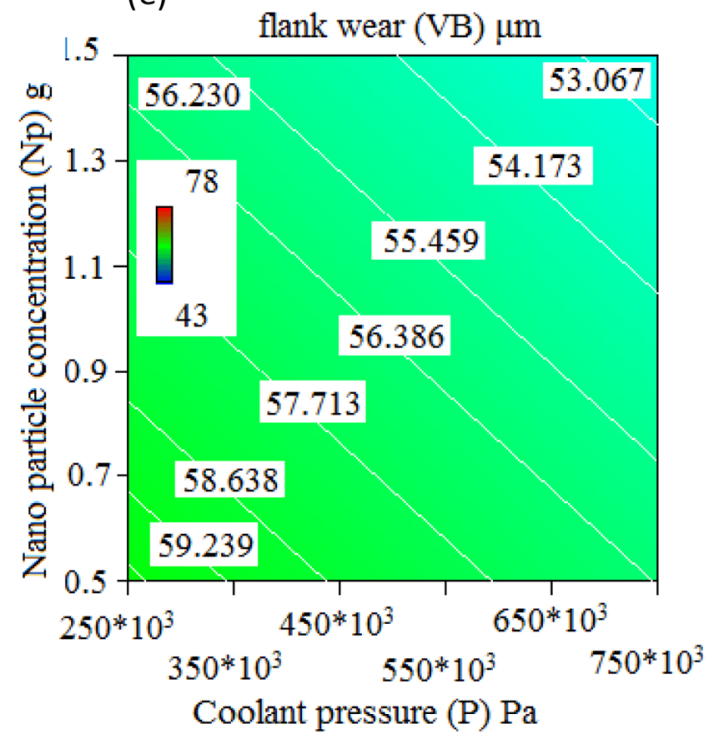

(b)

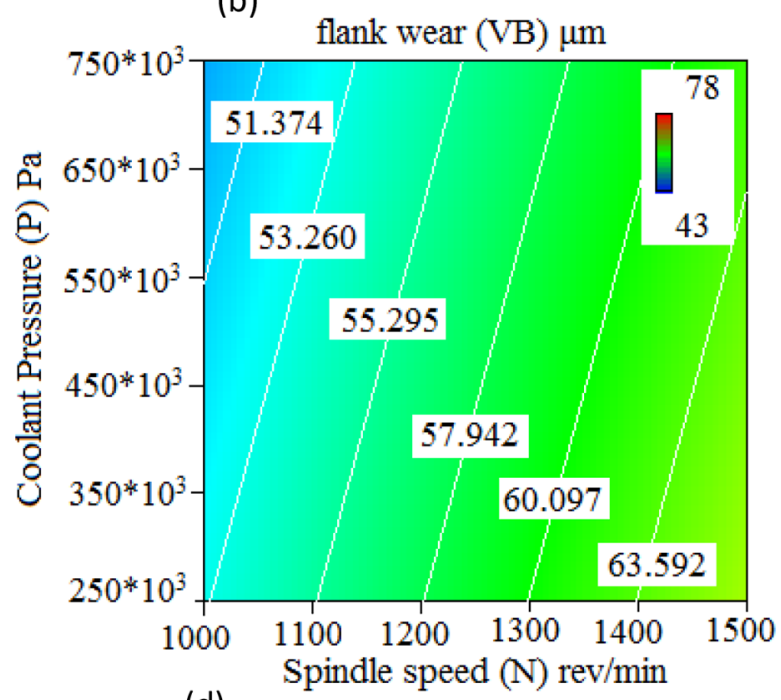

(d)

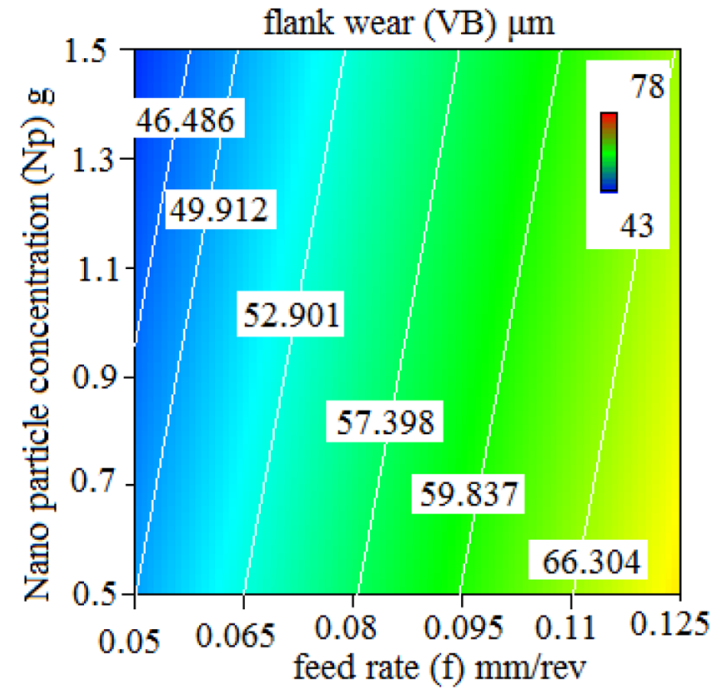

(f)

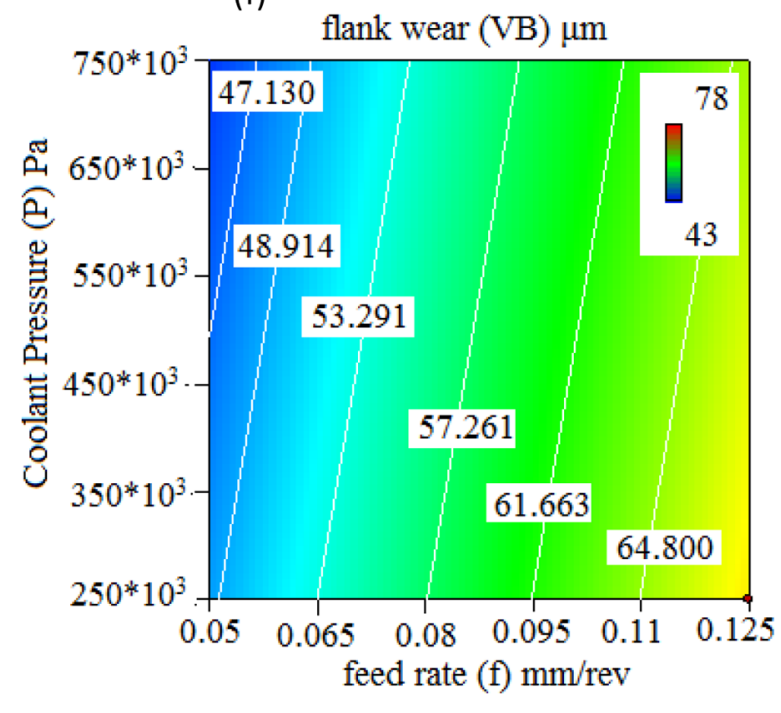

Fig. 12. (a-f) Effect of process parameters on 'VB', (a) Effect of ' $N$ ' at varying ' $f$ on 'VB'. (b) Effect of ' $N$ ' at varying ' $P$ ' on 'VB', (c) Effect of 'N' at varying 'Np' on 'VB' (d) Effect of 'f' at varying 'Np' on 'VB' (e) Effect of 'P' at varying 'Np' on 'VB', (f) Effect of ' $f$ ' at varying ' $\mathrm{P}$ ' on 'VB'. 

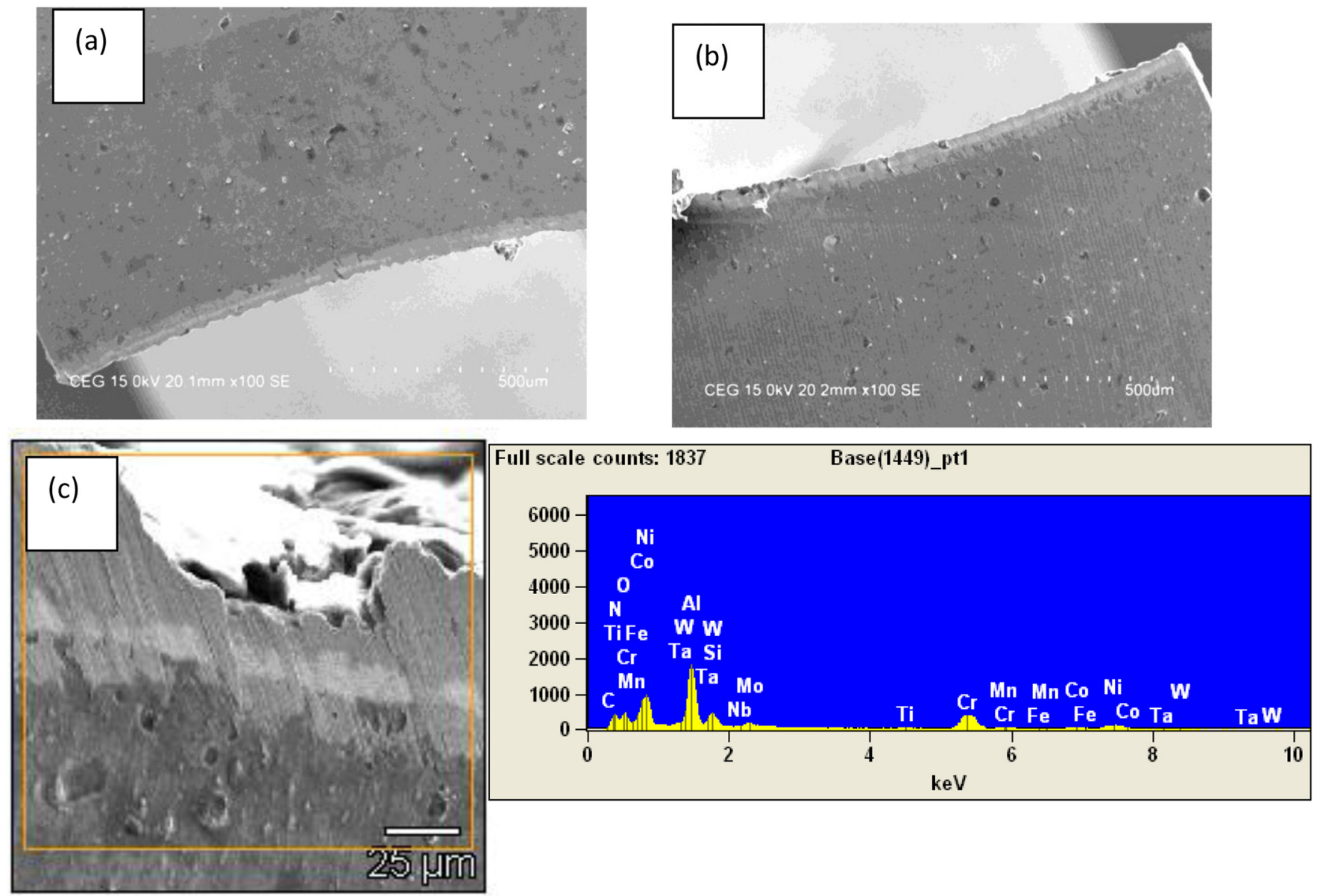

Fig. 13. (a-c) SEM Images of worn out drill at (a) $\mathrm{N}=1250(\mathrm{rpm}), \mathrm{f}=0.05(\mathrm{~mm} / \mathrm{rev}), \mathrm{P}=500^{*} 10^{3}(\mathrm{~Pa}), \mathrm{NP}=1.5 \%$ (g): $(\mathrm{VB}-42 \mu \mathrm{m})$, (b) $\mathrm{N}=1000(\mathrm{rpm}), \mathrm{f}=0.125(\mathrm{~mm} / \mathrm{rev}), \mathrm{P}=750^{*} 10^{3}(\mathrm{~Pa}), \mathrm{NP}=1.5 \%(\mathrm{~g}):(\mathrm{VB}-59 \mu \mathrm{m})$ and $(\mathrm{c})$ EDS analysis of worn out drill at $\mathrm{N}=1250(\mathrm{rpm}), \mathrm{f}=0.125(\mathrm{~mm} / \mathrm{rev}), \mathrm{P}=2500^{*} 103(\mathrm{~Pa}), \mathrm{NP}=1 \%(\mathrm{~g})$ : (VB-69 $(\mu \mathrm{m})$.

higher flank value is noted. At higher level of coolant pressure and lower level of spindle speed, the lowest flank wear is noted. The flank wear at high level of spindle speed and low level of coolant pressure (VB- $63.592 \mu \mathrm{m}$ ) is 1.235 times higher than the flank wear at low level of speed of the spindle and higher level of coolant pressure (VB$51.374 \mu \mathrm{m})$. The same trend was reported by [15]. Figure 12c exhibits the impact of speed of the spindle at varying Np on the flank wear. Higher flank wear is observed at higher level of speed of the spindle and lower level of nano particle concentration. Lowest flank wear is observed at high concentration of nanoparticles and low spindle speed. It would be due to decrease of penetration to tool/ chip interface because of increase in viscosity of nanocutting fluid [16]. Figure 12d shows the influence of the feed rate at various $\mathrm{Np}$ on the flank wear. High flank wear is observed at higher feed rate and lowest level of concentration of nano particles. Lowest flank is noted at higher level of nano particle concentration and lower. Figure 12e shows the effect of the pressure at different $\mathrm{Np}$ on the flank wear. At high pressure and high level of nano particles concentration, low flank wear is measured. At low pressure level and low level of $\mathrm{Np}$, high flank wear is noted. Figure $12 \mathrm{f}$ shows the effect of the feed rate at different coolant pressure on the flank wear. High flank wear value is observed at a higher feed rate and low level of pressure. Lowest flank wear is noted at low level of feed rate and high level of pressure. The change in cutting edge geometry can be seen from the SEM images as shown in Figure $13 \mathrm{a}-\mathrm{c}$ while drilling Nimonic C-263 alloy under different conditions.

Figure 13c show the EDS analysis and the traces of $\mathrm{Ni}$, $\mathrm{Ti}, \mathrm{Cr}, \mathrm{Ta}, \mathrm{Al}, \mathrm{Mo}, \mathrm{Mn}, \mathrm{Nb}, \mathrm{Cr}$, and Co were present on the worn out drill. Abrasion and diffusion are the major wear processes found during the drilling of this alloy using AlcrNo drill. Thus, the magnitude of the flank wear is high as the level of spindle speed and feed rate increases. It is also observed that the rate of flank wear is low as the level of nano particle concentration and coolant pressure increases. The flank wear is significantly influenced by spindle speed than nano particle concentration as the material is more sensitive to spindle more compare to other process parameters.

\subsection{Process parameter's effect on residual stresses}

Residual stresses in the drilling of this alloy were investigated in the form of tensile and compressive stresses. Tensile residual stresses are observed when the level of spindle speed increases, however the tensile residual 


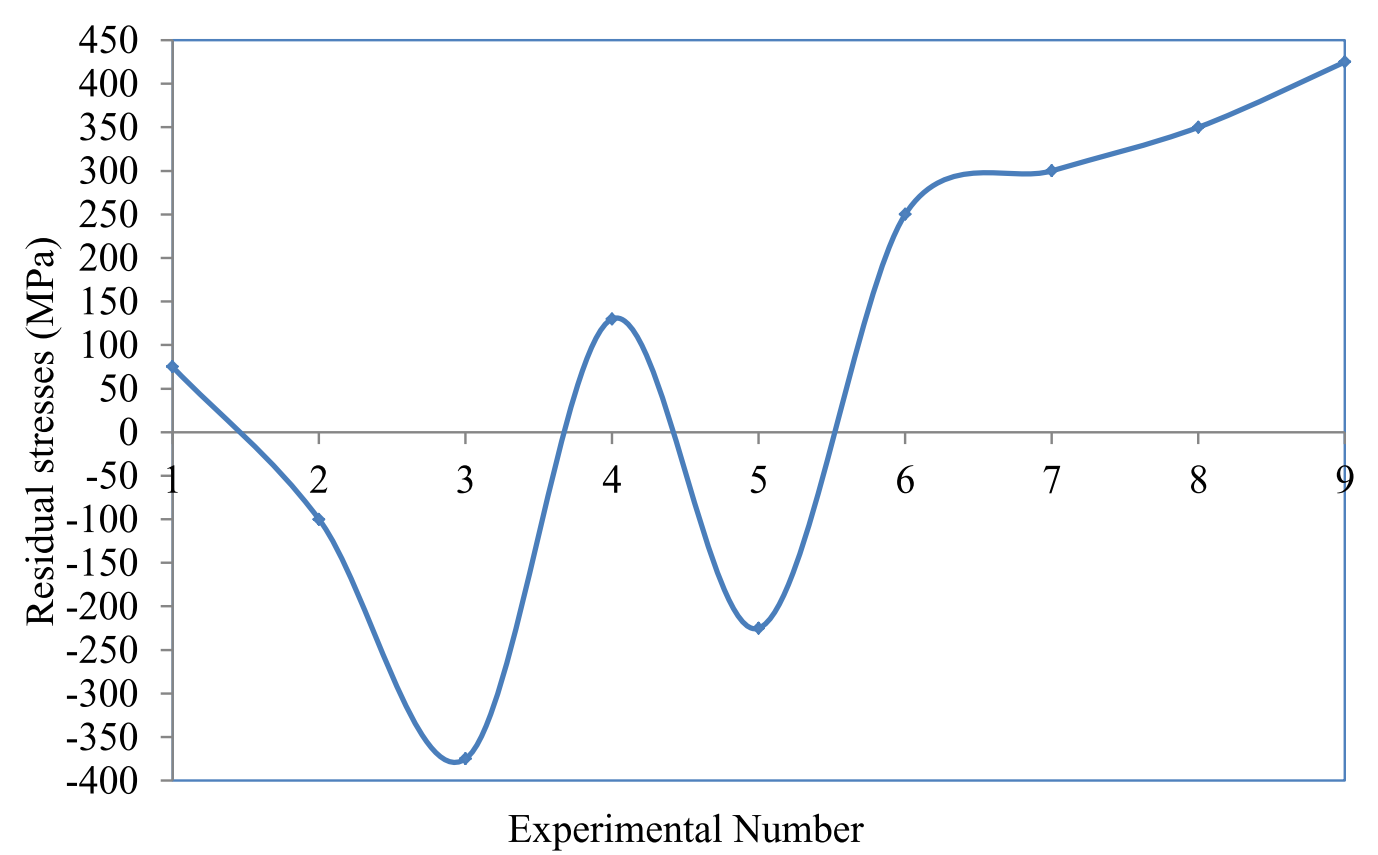

Fig. 14. Residual stresses at with respect to Experimental trails.

stresses become compressive as the feed level increases. The impact of spindle speed and feed rate is more on the generation of tensile and compressive residual stresses than the level of coolant pressure and nano particles concentrations. AlCrN Coated carbide drills were used to perform drilling tests on Nimonic C263 alloy to examine the impact of combinations of various drilling conditions on surface integrity via residual stress. The life and quality of machined part depends on the surface integrity. Surface finish includes topological parameters like mechanical properties such as residual stress and metallurgical improvements and surface roughness. During machining, because of the thermo-mechanical load, the material undergoes plastic deformation. It depends on the drilling condition, the geometry of the drill and the work material microstructure.

The drill experiences such as high resistance, work hardening, and high temperature around the tool-work interface in drilling this alloy owing to possessions of high temperature strength and low thermal conductivity of this alloy. These conditions contribute to residual stresses while drilling. In this investigation, the residual stresses were measured three times at each point on the drilled surface, with respect to all 9 experiments. The residual stresses produced by drilling the Nimonic C263 alloy under different process conditions are shown in Figure 14. From Figure 14, it is found that when the spindle speed level increases, tensile residual stresses are detected, but the residual tensile stresses become compressive when the level of feed rate increases. However, Figure 14 suggests that the influence of speed of the spindle and feed rate on the generation of tensile and compressive residual stresses is greater than the coolant pressure and concentration of nano particle.

When the level of feed rate increases, compressive residual stresses are generated, thus it indicates the impact of mechanical load. And as the level of spindle speed increases, tensile residual stresses are generated, and it shows the dominance of thermal load over the mechanical load. The impact on generation of tensile and compressive stresses while changing the level of pressure and weight percentage of nano particles are seen, however when compared to spindle speed and feed rate, it is low. The maximum tensile residual stress $(425 \mathrm{Mpa})$ is observed at high level of spindle speed, feed rate and middle level of pressure and low level weight percentage of nano particles. The minimum tensile residual stress $(75 \mathrm{Mpa})$ is observed at low level of spindle speed, feed rate, coolant pressure and a low level of weight percentage of nano particle. The maximum compressive stress $(-375 \mathrm{Mpa})$ is observed at low level of the spindle, high level of feed rate, coolant pressure and weight percentage of nano particles. The minimum compressive stress $(-100 \mathrm{Mpa})$ is observed at low level of spindle speed, middle level of feed rate, low level of pressure and middle level of weight percentage of nano particles.

\subsection{Modelling of machining parameters}

\subsubsection{Analysis of variance}

The response surface regression model was developed for the responses such as Temperature at drill cutting edge, thrust force, surface roughness and flank wear in drilling Nimonic C263 alloy. A design expert-expert version-10 tool was used for modelling and analysis. The experimental results and predicted values of the responses are shown in Table 4. Tables 5-7 show the ANOVA (F-Value), ANOVA (P-Value) and percentage contribution respectively for the responses. The developed model is more than adequate to determine the thrust force $\left(\mathrm{F}_{\mathrm{z}}\right)$ based on the ' $F$ ' level, since this model has a ' $F$ ' value of 32.74 and a Prop $>$ F value of less than 0.05 . The feed rate F-value is 
Table 4. Experimental results predicted values of responses under nano fluid mixed MQL condition using AlCrN coated carbide drill.

\begin{tabular}{|c|c|c|c|c|c|c|c|c|c|c|c|c|}
\hline \multirow[t]{2}{*}{ Exp. no } & \multicolumn{4}{|c|}{ Level of the process parameters } & \multicolumn{4}{|c|}{ Experimental results } & \multicolumn{4}{|c|}{ Predicted values } \\
\hline & $\mathrm{N}$ & $f^{\prime}$ & $\mathrm{P}$ & $\mathrm{Np}$ & $\mathrm{F}_{\mathrm{z}}(\mathrm{N})$ & $\Theta\left({ }^{\circ} \mathrm{C}\right)$ & $\mathrm{R}_{\mathrm{a}}(\mu \mathrm{m})$ & $\mathrm{VB}(\mathrm{mm})$ & $\mathrm{F}_{\mathrm{z}}(\mathrm{N})$ & $\Theta\left({ }^{\circ} \mathrm{C}\right)$ & $\mathrm{R}_{\mathrm{a}}(\mu \mathrm{m})$ & $\mathrm{VB}(\mathrm{mm})$ \\
\hline 1 & 1 & 1 & 1 & 1 & 530 & 257 & 1.07 & 45 & 524 & 253 & 1.12 & 43 \\
\hline 2 & 1 & 2 & 2 & 2 & 555 & 240 & 1.17 & 54 & 564 & 236 & 1.21 & 54 \\
\hline 3 & 1 & 3 & 3 & 3 & 590 & 224 & 1.18 & 59 & 582 & 218 & 1.23 & 57 \\
\hline 4 & 2 & 1 & 2 & 3 & 490 & 263 & 0.92 & 43 & 491 & 269 & 0.71 & 44 \\
\hline 5 & 2 & 2 & 3 & 1 & 525 & 270 & 1.1 & 59 & 534 & 286 & 1.02 & 61 \\
\hline 6 & 2 & 3 & 1 & 2 & 570 & 287 & 0.98 & 69 & 566 & 288 & 0.98 & 70 \\
\hline 7 & 3 & 1 & 3 & 2 & 465 & 329 & 0.36 & 53 & 460 & 319 & 0.51 & 51 \\
\hline 8 & 3 & 2 & 1 & 3 & 510 & 317 & 0.47 & 68 & 515 & 321 & 0.54 & 67 \\
\hline 9 & 3 & 3 & 2 & 1 & 540 & 346 & 0.86 & 78 & 535 & 338 & 0.79 & 77 \\
\hline
\end{tabular}

Table 5. ANOVA (F-value) table for the responses.

\begin{tabular}{llllllll}
\hline S. no & Source & $R^{2}(\%)$ & \multicolumn{5}{c}{ F-value } \\
\cline { 4 - 8 } & & & Model & $\mathrm{N}(\mathrm{rpm})$ & $\mathrm{f}(\mathrm{mm} / \mathrm{rev})$ & $\mathrm{P}(\mathrm{Pa})$ & $\mathrm{Np}(\%)(\mathrm{g})$ \\
\hline 1 & $\mathrm{~F}_{\mathrm{z}}$ & 97.04 & 32.74 & 47.31 & 81.96 & 1.66 & 0.046 \\
2 & $\Theta$ & 96.13 & 24.80 & 91.50 & $5.933 \mathrm{E}-003$ & 1.80 & 5.93 \\
2 & $\mathrm{R}_{\mathrm{a}}$ & 86.95 & 6.66 & 21.78 & 3.25 & 0.13 & 1.51 \\
3 & $\mathrm{VB}$ & 98.54 & 67.55 & 72.86 & 185.76 & 5.24 & 6.24 \\
\hline
\end{tabular}

Table 6. ANOVA (P-value) table for the responses.

\begin{tabular}{lllllll}
\hline S. no & Source & \multicolumn{5}{c}{ P-value } \\
\cline { 3 - 7 } & & Model & $\mathrm{N}(\mathrm{rpm})$ & $\mathrm{f}(\mathrm{mm} / \mathrm{rev})$ & $\mathrm{P}(\mathrm{Pa})$ & $\mathrm{Np}(\%)(\mathrm{g})$ \\
\hline 1 & $\mathrm{~F}_{\mathrm{z}}$ & 0.0026 & 0.0023 & 0.0008 & 0.266 & 0.840 \\
2 & $\Theta$ & 0.004 & 0.0007 & 0.9423 & 0.250 & 0.071 \\
2 & $\mathrm{R}_{\mathrm{a}}$ & 0.0466 & 0.0095 & 0.145 & 0.741 & 0.286 \\
3 & $\mathrm{VB}$ & 0.0006 & 0.0010 & 0.0002 & 0.083 & 0.066 \\
\hline
\end{tabular}

Table 7. Percentage contribution for the responses.

\begin{tabular}{|c|c|c|c|c|c|c|c|}
\hline \multirow[t]{2}{*}{ S. no } & \multirow[t]{2}{*}{ Source } & \multirow[t]{2}{*}{$R^{2}(\%)$} & \multicolumn{5}{|c|}{ Percentage contribution (\%) } \\
\hline & & & $\mathrm{N}(\mathrm{rpm})$ & $\mathrm{f}(\mathrm{mm} / \mathrm{rev})$ & $\mathrm{P}(\mathrm{Pa})$ & $\mathrm{Np}(\%)(\mathrm{g})$ & Error \\
\hline 1 & $\mathrm{~F}_{\mathrm{z}}$ & 97.04 & 35.5 & 60 & 1.23 & 0.03 & 2.95 \\
\hline 2 & $\Theta$ & 96.13 & 88.63 & 0.0057 & 1.73 & 5.74 & 3.87 \\
\hline 2 & $\mathrm{R}_{\mathrm{a}}$ & 86.95 & 71.42 & 10.57 & 0.0001 & 7.28 & 12.14 \\
\hline 3 & VB & 98.54 & 26.581 & 67.76 & 1.91 & 2.277 & 1.45 \\
\hline
\end{tabular}

high (F-81.96), when compared to spindle speed (F-47.31), thereby suggesting its higher effect on the thrust force. The effectiveness of the thrust force model is confirmed as this model has $R^{2}$ value of $R^{2}=97.04 \%$ for thrust force. The $R^{2}$ value represents the confidence in regression, and the high value of $R^{2}$ assures a higher correlation between then experimental trail results and predicted results. The RSM-based Thrust Force model is 
Table 8. The goals set and the limits used for the optimization.

\begin{tabular}{llllllc}
\hline Parameter \& response & Goal & $\begin{array}{l}\text { Lower } \\
\text { limit }\end{array}$ & $\begin{array}{l}\text { Upper } \\
\text { limit }\end{array}$ & $\begin{array}{l}\text { Lower } \\
\text { weight }\end{array}$ & $\begin{array}{l}\text { Upper } \\
\text { weight }\end{array}$ & Importance \\
\hline $\mathrm{N}(\mathrm{rev} / \mathrm{min})$ & is in range & 1000 & 1500 & 1 & 1 & 3 \\
$f(\mathrm{~mm} / \mathrm{rev})$ & is in range & 0.05 & 0.125 & 1 & 1 & 3 \\
Coolant Pressure $(\mathrm{Pa})$ & is in range & $250 \times 10^{3}$ & $750 \times 10^{3}$ & 1 & 1 & 3 \\
Weight percentage of Nano Particle $(\mathrm{g})$ & is in range & 0.5 & 1.5 & & & \\
$\mathrm{~F}_{\mathrm{z}}(\mathrm{N})$ & Minimize & 465 & 590 & 1 & 1 & 3 \\
Temperature at drill cutting edge $\left({ }^{\circ} \mathrm{C}\right)$ & & 224 & 346 & & & \\
$\mathrm{R}_{\mathrm{a}}(\mu \mathrm{m})$ & Minimize & 0.366 & 1.185 & 1 & 1 & 3 \\
$\mathrm{VB}(\mu \mathrm{m})$ & Minimize & 0.0427 & 0.078 & 1 & 1 & 3 \\
\hline
\end{tabular}

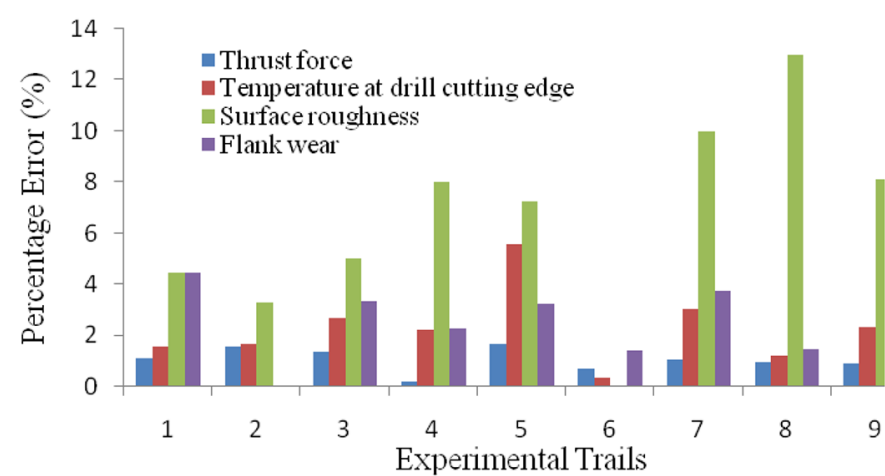

Fig. 15. Percentage Error between experimental and predicted values.

given in equation (1).

$$
\begin{aligned}
F_{z}= & +591.309-0.10667 \times V+919.047 \times f \\
& -2.0000 \times P-1.66667 \times \mathrm{Np} \%
\end{aligned}
$$

The developed model is considered to be satisfactory to estimate the temperature at drill cutting edge $(\Theta)$, since this model has a ' $\mathrm{F}$ ' value of 24.1 and a Prop $>\mathrm{F}$ value of less than 0.05. The F-value of the spindle speed is high (F- 91.50), followed by nano particle concentration (F-5.93) and coolant pressure (F-1.80), indicating the higher influence of temperature at drill cutting edge. The effectiveness of the model for the prediction of temperature at drill cutting edge is confirmed as the model has $R^{2}$ value of $96.13 \%$. The RSM-based model is designed to determine temperature at drill cutting edge and is given in equation (2).

$$
\begin{aligned}
\Theta\left({ }^{\circ} \mathrm{C}\right)= & +90.40476+0.180667 \times V+9.52381 \times f \\
& -2.53333 \times P-23 \times \mathrm{Np} \%
\end{aligned}
$$

The developed model is more competent to predict the surface roughness, as this model has ' $\mathrm{F}$ ' value of 6.66 and Prop $>\mathrm{F}$ less than 0.05 . The $\mathrm{F}$-value of the spindle speed is high (F-21.78) compared to feed rate (F-3.25). Thus, this reveals the greater influence of spindle speed on the surface roughness followed by feed rate, coolant pressure \& nano particle concentration. The effectiveness of the model is proven as this model has $R^{2}=86.95 \%$. The RSM-based model is designed to determine surface roughness is given in equation (3).

$$
\begin{aligned}
\mathrm{Ra}= & +2.18-1.15267 \mathrm{E}-003 \times V+2.91429 \times f \\
& +8.73333 \mathrm{E}-003 \times P-0.151667 \times \mathrm{Np}
\end{aligned}
$$

The developed model is more competent to predict the Flank Wear, as this model has ' $\mathrm{F}$ ' value of 67.53 and Prop $>$ $\mathrm{F}$ less than 0.05 . The $\mathrm{F}$-value of the feed rate is high (F-185.76), followed by the speed of the spindle (F-72.86), suggesting the greater impact of feed rate on Flank Wear. The validity of the flank wear model is verified as this model has $R^{2}=98.54 \%$. The model was developed to predict flank wear based on RSM and is given in equation (4).

$$
\begin{aligned}
\mathrm{VB}= & +5.97619+0.02733 \times V+285.7142 \times f \\
& -0.73333 \times P-4.0000 \times \mathrm{Np}
\end{aligned}
$$

From the Tables $5-7$, it is identified that feed rate has greater influence on flank wear followed by speed of the spindle, coolant pressure and nano particles concentration. Figure 15 shows the percentage of error between the experimental and predicted values from the RSM model which is around $10 \%$. These results showed that the predictive models are found to be the most effective method for the prediction of the responses.

\subsubsection{Multi response optimization}

The RSM optimization based on desirability is conducted for multi-responses. Table 8 indicates the target, the upper and lower limits, the weights, and the importance of the given factors. Optimization is applied on a combination of goals. The goals include all four factors and responses. The goal is to 'minimize' the thrust force, temperature at drill cutting edge, surface roughness and flank wear. The goal assigned for the factors is 'within limits'. Different best solutions were obtained with regard to $\mathrm{AlCrN}$ Coated carbide drill using the desirability based approach. 
Table 9. Best solutions for optimization.

\begin{tabular}{llllllllll}
\hline S. no & $\mathrm{N}(\mathrm{rev} / \mathrm{min})$ & $\mathrm{f}(\mathrm{mm} / \mathrm{rev})$ & $\mathrm{P}(\mathrm{Pa})$ & $\mathrm{Np}(\mathrm{g})$ & $\mathrm{F}_{\mathrm{z}}(\mathrm{N})$ & $\Theta\left({ }^{\circ} \mathrm{C}\right)$ & $\mathrm{R}_{\mathrm{a}}(\mu \mathrm{m})$ & $\mathrm{V}_{\mathrm{B}}(\mathrm{mm})$ & Desirability \\
\hline 1 & 1297 & 0.05 & $750^{*} 10^{3}$ & 1.5 & 481 & 271 & 0.673 & 44 & 0.752 \\
\hline
\end{tabular}

Table 10. Best solutions for optimization confirmation experiment and results.

\begin{tabular}{|c|c|c|c|c|c|c|c|c|c|c|c|c|}
\hline \multirow[t]{2}{*}{ S. no } & \multirow[t]{2}{*}{$\mathrm{N}(\mathrm{rpm})$} & \multirow[t]{2}{*}{$\mathrm{f}(\mathrm{mm} / \mathrm{rev})$} & \multirow[t]{2}{*}{$\mathrm{P}(\mathrm{Pa})$} & \multirow[t]{2}{*}{ Np-\% (g) } & \multicolumn{2}{|c|}{$\mathrm{F}_{\mathrm{z}}(\mathrm{N})$} & \multicolumn{2}{|c|}{$\Theta\left({ }^{\circ} \mathrm{C}\right)$} & \multicolumn{2}{|c|}{$\mathrm{R}_{\mathrm{a}}(\mu \mathrm{m})$} & \multicolumn{2}{|c|}{$\mathrm{VB}(\mu \mathrm{m})$} \\
\hline & & & & & Exp & Pred & Exp & Pred & Exp & Pred & Exp & Pred \\
\hline 1 & 1296 & 0.05 & $750 \times 10^{3}$ & 1.5 & 510 & 504 & 246 & 244 & 0.865 & 0.849 & 45 & 41 \\
\hline
\end{tabular}

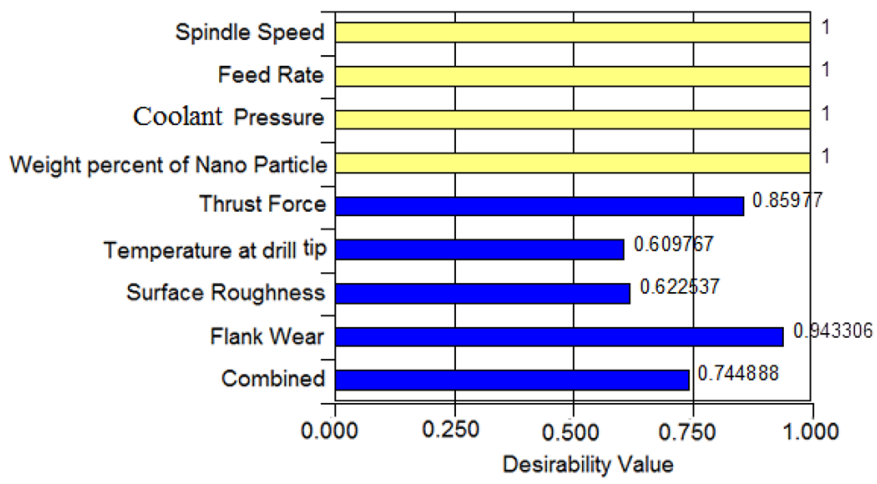

Fig. 16. Histogram of desirability for the best solution.

The goals and the limits sets for optimization are shown in Table 8 . The best solution and the confirmation of experimental results is exhibited in Tables 9 and 10 respectively. The histogram of the desirability of the best solution is shown in Figure 16 and the bars indicate the desirability values for the process parameters and for the responses such as thrust force, temperature at drill cutting edge, surface roughness and flank wear respectively. The combined desirability value is specified by the last bar. The validation tests were performed for the optimal solutions. The confirmation tests were conducted at N-1296 rev/min, $\mathrm{f}-0.05 \mathrm{~mm} / \mathrm{rev}$, Pressure $=750 \times 10^{3} \mathrm{~Pa}$ and $\mathrm{Np}=1.50 \% \mathrm{~g}$. The validation test results and the predicted results by optimization are tabulated in Table 10 . The result indicates that the predicted values are near to the value of experimental results.

\section{Conclusions}

During the drilling of Nimonic C263 alloy with AlcrN coated carbide insert, the present work focused on the effect of process parameters such as spindle speed, feed rate, coolant pressure and $\mathrm{Al}_{2} \mathrm{O}_{3}$ Nano particle concentration on thrust force, temperature at cutting edge, surface roughness and tool wear. Multi regression equations and the Taguchi method were used to develop predicted models. Finally, Machining parameters are optimized and validated. The important findings of the study are summarized as follows:

- It was found that optimum parameter design for multi responses was spindle speed-1297 (rev/min), feed rate$0.05(\mathrm{~mm} / \mathrm{rev})$, coolant pressure- $750 \times 10^{3}(\mathrm{~Pa})$, Nano particle concentration-1.5 (g).

- Speed of the Spindle was identified as a dominant factor on thrust force followed by feed rate, coolant pressure and nano particle concentration. Feed rate is identified as a major factor on temperature at drill cutting edge followed by spindle speed, nano particle concentration and coolant pressure.

- The temperature at drill cutting edge increases at higher level of spindle speed, feed rate, and lower level of coolant pressure, lower level of nano particle concentration. The surface roughness increases at higher level of feed rate, lower level of spindle speed, lower level of coolant pressure, and lower level of concentration of nano particles.

- Feed rate is identified as important factor on the flank wear followed by spindle speed, nano particle concentration, and coolant pressure. At higher level of spindle speed, feed rate, lower level of coolant pressure and lower level of nano particles concentration, the flank wear increases.

- The error percentage obtained in comparing the predicted and experimental values for the responses is within $10 \%$. As the feed rate level increases, compressive residual stresses are generated; this indicates the impact of mechanical load. As the level of spindle speed increases, tensile residual stresses are generated; this indicates the dominance of thermal load over mechanical load.

\section{References}

1. C. Ezilarasan, V.S. Senthil Kumar, A. Velayudham, K. Palanikumar, Modeling and analysis of surface roughness on machining of Nimonic C-263 alloy by PVD coated carbide insert, Trans. Nonferrous Metals Soc. China 21 (2011) 1986-1994 
2. C. Ezilarasan, V.S. Senthil Kumar, A. Velayudham, Effect of machining parameters on surface integrity in machining nimonic C-263 super alloy using whisker-reinforced ceramic insert, J. Mater. Eng. Perform. 22 (2013) 1619-1628

3. R. Hood, S.L. Soo, D.K. Aspinwall, P. Andrews, C. Sage, Twist drilling of Haynes 282 super alloy, Proc. Eng. 19 (2011) 150-155

4. A.R. Erween, H. Sasahara, An analysis of surface integrity when drilling Inconel 718 using palm oil and synthetic ester under MQL condition, Int. J. Mach. Sci. Technol. 15 (2011) 76-90

5. S.A. Lawal, I.A. Choudhury, Y. Nukman, A critical assessment of lubrication techniques in machining process: case for minimum quantity lubrication, journal of cleaner production, J. Clean. Prod. 41 (2013) 210-221

6. A.M.M. Nazmul Ahasm, M.G. Kibria, M.R. Ahmed, An experimental study on the effect of minimum quantity lubrication on drilling AISI 1040 steel, Gazi Univ. J. Sci. 28 (2015) 161-167

7. I. Shyha, S. Gariani, M. Bhatti, Investigation of cutting tools and working conditions effects when cutting Ti-6Al-4V using vegetable oil based cutting fluid, Proc. Eng. 132 (2015) $577-584$

8. A.T. Kuzu, K. Rahimzadeh Berenji, B.C. Ekim, M. Bakkal, The thermal modelling of deep-hole drilling process under MQL condition, J. Manuf. Process. 29 (2017) 194-203

9. N. Swain, P. Kumar, G. Srinivas, S. Ravi Shankar, B. Harish, Mechanical micro-drilling of Nimonic 80A super alloy using uncoated and TiAlN coated micro drills, Mater. Manuf. Proc. 32 (2017) 1537-1546
10. P. Subhash Chandra Bose, C.S.P. Rao, K. Jawale, Role of MQL and nano fluids on the machining of Nicrofer C263. In: 5th International \&6 26th All India Manufacturing Technology, Design and Research Conference, 2014, pp. 363-363

11. R.S. Revuru, N.R. Posinasetti, V.S.N. Venkata Ramana, M. Amrita, Application of cutting fluids in machining of titanium alloys - a review, Int. J. Adv. Manuf. Technol. 91 (2017) 2477-2498

12. O.A. Oluwole, H. Che, V. Songmene, C. Katsari, S. Yue, Machinability of rene 65 superalloy, Materials 12 (2019) 20-34.

13. C. Darshan, S. Jain, M. Dogra, M.K. Gupta, M. Mia, R. Haque, Influence of dry and solid lubricant-assisted MQL cooling conditions on the machinability of Inconel 718 alloy with textured tool, J. Adv. Manuf. Technol. 105 (2019) $1835-1849$

14. H.V. Shete, M.S. Sohani, Effect of process parameters on hole diameter accuracy in high pressure through coolant peck drilling using Taguchi technique, Int. J. Mater. Form. Mach. Proc. 5 (2018) 1-20

15. V. Anandan, M. Naresh Babu, N. Muthukrishna, M. Dinesh Babu, Performance of silver nano fluids with minimum quantity lubrication in turning on titanium: a phase to green manufacturing, J. Braz. Soc. Mech. Sci. Eng. 42 (2020) 198

16. F. Gunana, T. Kıvak, Ç.V. Yıldırımc, M. Sarıkaya, Performance evaluation of MQL with AL2O3 mixed nanofluids prepared at different concentrations in milling of Hastelloy C276 alloy, Int. J. Mater. Res. Technol. 9 (2020) 10386-10400

Cite this article as: Chakaravarthy Ezilarasan, Meenaskshi Sundaram Nagaraj, A. John Presin Kumar, A. Velayudham, Rishab Betala, Experimental analysis of process parameters in drilling nimonic C263 alloy under nano fluid mixed MQL environment, Manufacturing Rev. 8, 2 (2021) 